\title{
Borrelioses, agentes e vetores ${ }^{1}$
}

\author{
Cleber O. Soares ${ }^{2}$, Marcia M. Ishikawa ${ }^{2}$, Adivaldo H. Fonseca ${ }^{3}$ e Natalino \\ H. Yoshinari ${ }^{4}$
}

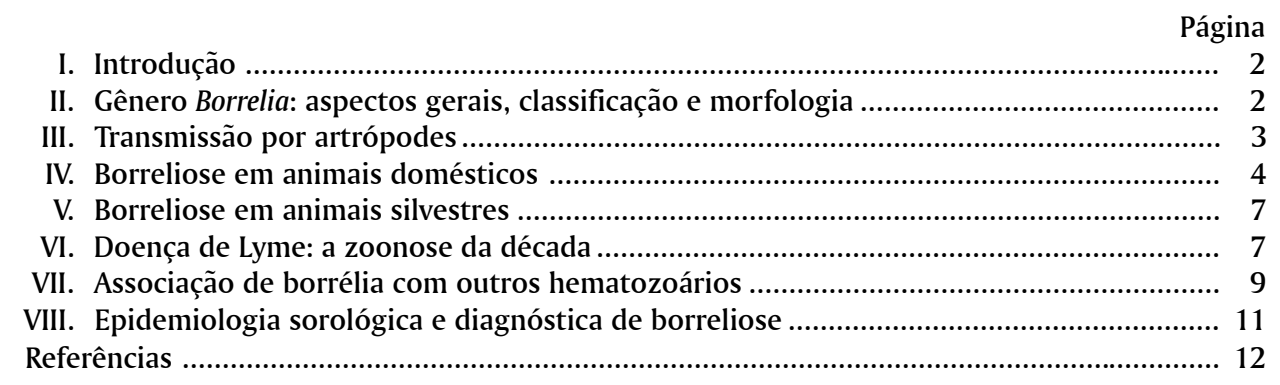

\begin{abstract}
Soares C.O., Ishikawa M.M., Fonseca A.H. \& Yoshinari, N.H. 2000. [Borrelioses, agents and vectors: a review.] Borrelioses, agentes e vetores. Pesquisa Veterinária Brasileira 20(1):1-19. Depto Epidemiologia e Saúde Pública, Instituto de Veterinária, Univ. Fed. Rural do Rio de Janeiro, Km 47, Seropédica, RJ 23851-970, Brazil.

Borrelioses are infectous diseases caused by spirochaetes of the genus Borrelia. They are born mainly through ticks at animals and/or human beings. In this review are shown and discussed five groups of diseases determined by borrelia, general characteristics of the spirochaetes, aspects related to transmission by arthropods, biological and pathological aspects of the diseases in domestic and wild animals, Lyme disease as an important zoonosis, the association of borrelia with other hematozoa agents, the diagnostic methods and the comparative epidemiology with data obtained from Brazil and other countries. The borrelioses have pathological, clinical and epidemiological characteristics which vary according to physiographic regions due to the existence of different species, genospecies and strains of borrelia, of arthropod vectors, vector-agent relationship and of different ecocystems.
\end{abstract}

INDEX TERMS: Borreliosis, ticks, Borrelia spp., relapsing fever, avian borreliosis, bovine borreliosis, Lyme disease, epizootic bovine abortion.

RESUMO.- As borrelioses são enfermidades infecciosas determinadas por espiroquetas do gênero Borrelia, agentes transmissíveis, principalmente, por carrapatos aos animais e/ou ao homem. Nesta revisão são apresentadas e discutidas as enfermidades determinadas por borrélias, bem como as

\footnotetext{
${ }^{1}$ Aceito para publicação em 29 de junho de 1999.

Trabalho realizado sob os auspícios do CNPq. Parte da Tese de Mestrado do primeiro autor junto ao Curso de Pós-Graduação em Medicina Veterinária - Parasitologia Veterinária (CPGMV-PV), Universidade Federal Rural do Rio de Janeiro (UFRRJ).

${ }^{2}$ Doutorandos CPGMV-PV, UFRRJ. Km 47, Seropédica, RJ 23851-970. e-mail: csoares@ufrrj.br

${ }^{3}$ Departamento de Epidemiologia e Saúde Pública. UFRRJ. e-mail: adivaldo@ufrrj.br

${ }^{4}$ Departamento de Reumatologia, Faculdade de Medicina, Universidade de São Paulo.
}

características gerais das espiroquetas, os aspectos relacionados a transmissão por artrópodes, as enfermidades nos animais domésticos e silvestres, quanto aos aspectos biológicos e patológicos, a doença de Lyme como principal zoonose do grupo, a associação de borrélia com outros agentes hematozoários e os métodos diagnósticos e a epidemiologia comparativa entre dados obtidos no Brasil com os de outros países. Estas borrelioses possuem características patológicas, clínicas e epidemiológicas variadas de acordo à região fisiográfica, devido à existência de distintas espécies, genoespécies e cepas; estes aspectos variam ainda em função dos artrópodes vetores, da interação vetor-patógeno e dos ecossistemas distintos.

TERMOS DE INDEXAÇÃO: Borreliose, carrapatos, Borrelia spp., febre recurrente, borreliose aviária, borreliose bovina, doença de Lyme, aborto epizoótico bovino. 


\section{INTRODUÇÃO}

Atualmente são reconhecidas cinco enfermidades causadas por microrganismos do gênero Borrelia Swellengrebel, 1907, que afetam os animais e/ou o homem. Febre recurrente, a primeira borreliose descrita, causa doença no homem, e tem como agente Borrelia recurrentis "lato sensu" com mais de 20 espécies, cujos vetores são carrapatos do gênero Ornithodorus e piolhos do gênero Pediculus (Pavlovsky 1965, Hoogstraal 1985). A espiroquetose aviária, descrita em seguida, é determinada por $B$. anserina, cujos vetores são os carrapatos do gênero Argas, em diferentes aves (Quinn et al. 1994). A borreliose bovina, é causada por $B$. theileri, agente que também pode infectar ovinos e é transmitida por carrapatos ixodídeos, principalmente Boophilus microplus (Neitz 1956, Callow 1967, Matton \& Melckebeke 1990). A borreliose mais recente é o aborto epizoótico bovino, que tem como agente etiológico $B$. coriaceae e como vetor 0 . coriaceus (Johnson et al.1987, Zingg \& Lefebvre 1994).

A borreliose de Lyme acomete animais domésticos, silvestres e o homem e constitui uma doença de caráter multissistêmico com ampla distribuição geográfica (Bennett 1995). A doença de Lyme tem como agentes B. burgdorferi, em vários continentes, $B$. garinii (Baranton et al. 1992) na Europa, B. afzelii (Canica et al. 1993) na Europa e no Japão, $B$. japonica (Kawabata et al. 1993) no Japão, B. miyamotoi na Ásia (Postic et al. 1993), B. andersoni (Marconi et al. 1995) e $B$. lonestari (Barbour et al. 1996) na América do Norte, $B$. lusitaniae (Le Fleche et al. 1997) na Europa, B. valaisiana (Wang et al. 1997) na Europa e a genoespécie denominada DN 127 nos Estados Unidos da América. Esses agentes e suas variantes antigênicas são responsáveis pelas diversas apresentações clínicas da enfermidade (Bennett 1995, Silva \& Fikrig 1997).

$\mathrm{O}$ estudo epidemiológico das borrelioses tem como principal ferramenta imunológica o ensaio imunoenzimático ELISA (Steere 1989, Magnarelli et al. 1995c), embora outras técnicas como a imunofluorescência, imunoblotting e o PCR também sejam utilizadas como suporte no diagnóstico (Grodzicki \& Steere 1988, Lienbling et al. 1993). A existência de reação cruzada entre Borrelia sp. e Leptospira sp. tem sido relatada, embora não sendo significativa (Wells et al. 1993).

No Brasil, estudos soroepidemiológicos de borrelioses foram realizados em humanos (Yoshinari et al. 1993b, 1995) em cães (Joppert 1995, Soares 1998) e em bovinos (Ishikawa 1996, Fonseca et al. 1996), e a soroprevalência em todos os estudos apresentam valores próximos aos reportados em áreas endêmicas na América do Norte (Greene 1990).

Esta revisão tem por objetivo, apresentar os aspectos atuais relativos a biologia e transmissão de Borrelia spp., as enfermidades determinadas por estes agentes e suas associações com outros hematozoários, bem como a epidemiologia e os métodos de diagnósticos das borrelioses.

\section{GÊNERO BORRELIA: ASPECTOS GERAIS, CLASSIFICAÇÃO E MORFOLOGIA}

O gênero Borrelia Swellengrebel, 1907, foi assim denominado em homenagem a A. Borrel. Os microrganismos deste gênero possuem o formato helicoidal com 3 a 10 espiras e medem de 0,2 a $0,5 \mathrm{~mm}$ por 3 a $30 \mathrm{~mm}$. Este organismo tem protoplasma cilíndrico envolto pela membrana celular, da qual partem flagelos, possui externamente outra membrana contendo diversas proteínas de superfície, e não possui túbulos citoplasmáticos (Krieg \& Holt 1984, Barbour \& Hayes 1986).

Como membro da ordem Spirochaetales, família Spirochaetaceae, estas bactérias distinguem-se morfologicamente dos demais gêneros, desta família, por serem maiores, possuírem maior número de flagelos periplasmáticos (15 a 20) e menor número de espiras (Pfister et al. 1994, Quinn et al. 1994). Entretanto, dentro de uma única espécie pode ocorrer pleomorfismo (Bennett 1995). Estes agentes se reproduzem por fissão binária transversal, são microaerófilos (Austin 1993), o que os distingue dos demais gêneros, pois a maioria é aeróbico. Coram-se facilmente pelos corantes derivados da anilina e do Romanovski, são gram negativas, crescem à temperatura de $33^{\circ} \mathrm{C} \mathrm{em}$ meios artificiais e podem ser visualizadas através de microscopia de campo escuro, de contraste de fase ou ainda em tecidos, quando por colorações à base de prata (Barbour \& Hayes 1986, Quinn et al. 1994).

A primeira observação de espiroqueta foi reportada por Leeuwenhoek em 1681, em material oriundo da mucosa bucal e intestinal do homem. Em 1834, Ehrenberg descreveu Spirochaeta plicatilis, de vida livre. No entanto, a importância deste grupo se deu à descoberta de Obermeier em 1868 , publicada em 1873, quando verificou na Rússia, a presença de espiroquetas no sangue de indivíduos com febre recurrente (Pessoa 1963, Pavlovsky 1965). Este grupo de microrganismos teve classificação incerta por um longo período, ficando ora no grupo das algas, ora no das bactérias e ora no dos protozoários. Por sua conformação helicoidal, foi classificada, inicialmente, como alga Cyanophyceae e depois como bactéria do gênero Paraspirillum (Pêssoa 1963). As borrélias, contudo, por um longo tempo permaneceram dentro do antigo Filo Protozoa, Classe Spirochetes, e no gênero Borrelia (Brumpt 1927). Sua posição quanto aos protozoários se deu pela falta de polaridade, comum nos Protozoa; por encontrarem-se no sangue dos animais, foi relacionada ao gênero Trypanosoma, ficando por algum tempo no grupo Protoflagelata, já que também se caracteriza por ser transmitido por artrópodes (Brumpt 1927, Pêssoa 1963). Entretanto, a partir de 1948, os bacteriologistas sistematas colocaram-no como um grupo especial entre as bactérias (Pêssoa 1963, Krieg \& Holt 1984). A espécie tipo é B. anserina Sakharoff, 1891. As borrélias, na sua maioria são parasitas sanguineos de animais e do homem (Felsenfeld 1965, Barbour \& Hayes 1986), embora exerçam uma relação simbiótica com os carrapatos, especialmente argasídeos (Hoogstraal 1979).

As borrélias conhecidas, determinam cinco grupos de enfermidades distintas: (1) febre recurrente humana, ocasionada pelo grupo B. recurrentis Lebert, 1874, "lato sensu" (Quadro 1). É a enfermidade mais antiga causada por borrélia, talvez a mais antiga doença transmitida por artrópodes conhecida; há registros de sua ocorrência anterior ao início das civilizações egípcias e até hoje causou incontáveis óbitos (Brumpt 1927, Pêssoa 1963, Pavlovsky 1965, Barbour \& Hayes 
1986). (2) Borreliose aviária, determinada por uma única espécie, B. anserina Sakharoff, 1891, causa processo anemiante, febre, depressão e altas taxas de morbidade nas aves (Brumpt 1927, Diab \& Soliman 1977, Quinn et al. 1994). (3) Espiroquetose bovina, causada por $B$. theileri Laveran, 1903, determina anemia em ruminantes e eqüinos, considerada pouco patogênica (Koch et al. 1990, Quinn et al. 1994). (4) Borreliose de Lyme, causada pelo grupo B. burgdorferi Johnson, Schmid, Hyde, Steigerwalt \& Brenner, 1984 "lato sensu”, com nove espécies definidas e uma genoespécie não nomeada (Quadro 1) (Bennett 1995, Euzeby 1995, Marconi et al. 1995, Barbour et al. 1996, Le Fleche et al. 1997, Wang et al. 1997). (5) Aborto epizoótico bovino, enfermidade que acomete bovinos e cervídeos, determinada por B. coriaceae Johnson, Burgdorfer, Lane, Barbour, Hayes \& Hyde, 1987 (Breitschwerdt et al. 1994, Zingg \& Lefebvre 1994).

As espécies de borrélia foram nomeadas segundo seu vetor, por terem o modo de transmissão principalmente por carrapatos, embora os piolhos do gênero Pediculus transmitam $B$. recurrentis. Existe registros da transmissão de Leptospira pomona por Ornithodorus turicata (Burgdorfer 1956, Hoogstraal 1979). Atualmente a identificação das espécies se dá pela associação dos estudos biológico, bioquímico e molecular (Hoogstraal 1985, Barbour \& Hayes 1986, Marconi et al. 1995, Barbour et al. 1996, Silva \& Fikrig 1997).

\section{TRANSMISSÃO POR ARTRÓPODES}

As doenças transmitidas por artrópodes são as que mais acometem os animais e ao homem, principalmente, pelo fato da habilidade de dispersão do patógeno, além do envolvimento mecânico ou biológico do artrópode (Brumpt 1927, Pavlovsky 1965, Hoogstraal 1985, Schwan 1996). Na história da humanidade, segundo Pavlovsky (1965) e Hoogstraal (1985), nenhum grupo de enfermidade provocou tantos óbitos quanto as veiculadas por artrópodes. A peste bubônica dizimou aproximadamente dois terços da população européia na idade média (Pavlovsky 1965). A malária foi responsável por milhões de óbitos na história do homem, impossibilitou e dificultou a construção de rodovias, ferrovias, grandes pontes, a exploração vegetal e mineral. A Organização Mundial de Saúde estima que dois milhões de pessoas são acometidas, pela malária, e ocorrem cem mil óbito por ano no mundo (Roitt et al. 1997).

Sabe-se que as enfermidade transmitidas por artrópodes afetam os animais desde os primórdios da civilização, antes mesmo do surgimento do Homo sapiens. Acredita-se que essas doenças tenham a origem nos répteis primitivos, entre elas, a malária e as arboviroses (Brumpt 1927, Pavlovsky 1965, Garnham 1966). A história demonstra que as civilizações egípcias, como também as incas, maias e astecas, relatavam as enfermidades ocorrentes através de esculturas, pinturas e rituais (Pêssoa 1963, Pavlovsky 1965, Barbour \& Hayes 1986).

Entretanto, apenas em 1878, com a descoberta de Patric Manson, de que culicídeos veiculavam filarídeos, foi que os artrópodes começaram a assumir importância. A comprovação do envolvimento de patógeno com artrópode se deu quando Smith \& Kilborne (1893) descreveram a transmissão e o envolvimento biológico do carrapato Boophilus annulatus com o Piroplasmida Babesia bigemina; só então a comunidade científica aceitou esse importante papel dos artrópodes hematófagos.

Os carrapatos, segundo Balashov (1972), Soneshine (1991) e Schwan (1996), se constituem no segundo grupo que maior número de patógenos transmitem, sendo superados apenas pelos culicídeos. Os Carrapatos transmitem uma diversidade de vírus, bactérias, protozoários, fungos e nematódeos; além de excretarem/secretarem substâncias farmacologicamente ativas e/ou tóxicas (Hoogstraal 1985, Ribeiro et al. 1985, Uilenberg 1986, Ribeiro 1989, Spach et al. 1993, Randolph et al. 1996).

As borrélias são transmitidas primordialmente pelos carrapatos, embora, em raros casos, ou experimentalmente, sejam transmitidas por tabanídeos, culicídeos e sifonápteros (Magnarelli et al. 1986, 1987, Butler \& Denmark 1990). Dentre as espiroquetas, apenas as borrélias são transmitidas por ectoparasitos hematófagos, embora Burgdorfer (1956) discuta a possibilidade dos carrapatos argasídeos transmitirem leptospiras na natureza.

Os carrapatos são importantes na biologia das borrélias. Hoogstraal (1985), em memorável trabalho de revisão, reportou que elas desenvolvem-se como simbiontes nos artrópodes e atuam como parasitas nos animais e no homem. Restrepo et al. (1994), Schwan (1996) e Silva \& Fikrig (1997), reportaram que sucessivas infecções por borrélia sem o envolvimento do carrapato, diminuem sua patogenicidade, podendo tornar-se apatogênica. Hoogstraal (1985), Schwan (1996), Randolph et al. (1996) e Schwan (1996), verificaram que existe uma dependência bioquímica entre a espiroqueta e o vetor, que se dá principalmente ao nível de trato intestinal do carrapato, quando do desenvolvimento e multiplicação da borrélia. Este fenômeno, bem como a quimiotaxia da espiroqueta por determinados sítios do trato digestivo do carrapato estão relacionados à ativação de genes, presentes na borrélia, para determinadas fases do ciclo biológico (Barbour 1990, Fikrig et al. 1992, Restrepo et al. 1994, Silva \& Fikrig 1997).

O fenômeno de variação antigênica, quer no vetor, quer na evasão ao sistema imune do hospedeiro vertebrado pelas borrélias, é similar ao que ocorre com os hemoprotozoários, como em Babesia, Leishmania e Trypanosoma, que realizam trocas e escapes imunológicos determinados ora geneticamente, ora ambiental, o que pode ser uma mutação e irreversível (Burman et al. 1990, Van Der Ploeg et al. 1992, Restrepo et al. 1994, Silva \& Fikrig 1997, Roitt et al. 1997).

Outro fator relacionado à transmissão de borrélias é a temperatura ambiente em que vive o carrapato. A temperatura elevada é deletéria para muitas espécies de espiroquetas, dada sua influência no metabolismo, no balanço hídrico e no processo digestivo do vetor (Hoogstraal 1985, Shih et al. 1995a). O curso da infecção pode ser modificado pela temperatura quando da morte, ou da diapausa ou, principalmente, das alterações na síntese protéica do patógeno (Nakayama et al. 1989, Zung et al. 1989, Fingerle et al. 1995, Shih et al. 
1995b). Este fenômeno é comum em piroplasmídeos e arbovírus (Mclean et al. 1975, Dalgliesh \& Stewart 1976, Kramer et al. 1983, Lewengrub et al. 1989).

O crescimento e multiplicação da borrélia no carrapato são afetados por processos fisiológicos durante o ciclo vital do artrópode. Muitas espiroquetas podem morrer logo após a mudança de estágio do vetor, como também o carrapato pode sucumbir por um número excessivo de espiroquetas que podem lesar seus órgãos (Burgdorfer 1956, Balashov 1972, Smith et al. 1978, Hoogstraal 1985, Piesman et al. 1990, Schwan 1996).

O modo de transmissão das borrélias pode ser transovariano (vertical) e/ou transestadial (horizontal). Nas espécies transmitidas pelos argasídeos ocorre primordialmente a forma transovariana, o que é bem caracterizado no gênero Argas com $B$. anserina, embora haja também transmissão horizontal, principalmente com as borrélias do grupo da febre recurrente para Ornithodorus (Hoogstraal 1979, 1985, Barbour \& Hayes 1986). Contudo nos argasídeos, o modo de transmissão está intrinsecamente relacionado à cepa do carrapato, à região fisiográfica, à espécie de borrélia e ainda à associação com outros patógenos (Diab \& Soliman 1977, Zaher et al. 1977, Hoogstraal 1985).

Para os ácaros ixodídeos pode ocorrer ambos modos de transmissão (Smith et al. 1978, Randolph et al. 1996). Esse fenômeno foi melhor compreendido com os estudos da borreliose de Lyme, partindo-se de Ixodes dammini (=I. scapularis) (Oliver Jr et al. 1993), e demais espécies de Ixodes vetores de B. burgdorferi "lato sensu” (Burgdorfer et al. 1985, Anderson et al. 1987, Mather \& Mather 1990, Ewing et al. 1994) e quando da sua associação com babesiose e ehrlichiose (Spielman et al. 1979, 1985, Piesman et al. 1986, Spach et al. 1993, Anderson et al. 1993, Magnarelli et al. 1995a).

Nos argasídeos, todos os instares têm habilidade para transmitir borrélia, enquanto entre os ixodídeos, o estágio de ninfa parece ter maior importância epidemiológica na transmissão, manutenção e dispersão da espiroqueta, estando estes processos relacionados ao hospedeiro no qual o carrapato realize seu repasto (Benach et al. 1987, Lane \& Burgdorfer 1987, Lane \& Manweiler 1988, Telford \& Spielman 1989, Bouseman et al. 1990).

0 tempo de fixação no hospedeiro é relevante quanto à eficiência na transmissão. Estudos demonstraram que para os ixodídeos é necessário um tempo superior a 48 horas (Piesman et al. 1987, Falco \& Fish 1988, 1989, Falco et al. 1995), porém para os argasídeos o tempo de fixação não é relevante (Dodge 1973, Hoogstraal 1985, Smith et al. 1985), posto que nesta família ocorre a transmissão tanto via saliva quanto via líquido coxal; exceto na fase de larva, o repasto sanguineo se dá em poucos minutos (Balashov 1972, Hoogstraal 1985, Soneshine 1991), contra a exclusiva via salivar e o repasto lento dos ixodídeos (Soneshine 1991).

Os argasídeos têm potencial para transmitirem quase todas as borrélias (Hoogstraal 1985, Barbour \& Hayes 1986), enquanto nos ixodídeos o fenômeno é mais restrito. Dos cinco grupos de borrelioses, todas são transmitidas por carra- patos, tendo cada grupo sua (s) espécie (s) de espiroqueta e os respectivos artrópodes vetores (Quadro 1).

A relação Borrelia versus carrapato é tão estreita, que a espécie pode ser isolada e identificada com o auxílio do xenodiagnóstico (Appel et al. 1993). Antígenos salivares do carrapato podem ser inoculados junto com a espiroqueta, de forma a induzir determinadas expressões antigênicas pela borrélia e consequente resposta imunológica específica pelo hospedeiro, podendo estes antígenos serem utilizados para triagem epidemiológica e relacioná-los a Borrelia spp. (Barbour et al. 1983, Schwartz et al. 1990, 1993, Ewing et al. 1994). No momento da transmissão, a saliva do carrapato exerce ainda ações farmacológicas, como o bloqueio de células fagocitárias e inflamatórias, facilitando a penetração e disseminação do patógeno (Ribeiro et al. 1987, Urioste et al. 1994).

Embora o principal modo de transmissão de Borrelia seja por carrapatos, ela pode ocorrer ainda pela urina entre roedores, por transfusão sanguinea, transplante de tecido, por contato ou congenitamente em cães (Burgess et al. 1986a, Hyde et al. 1989, Dorward et al. 1991, Burgdorfer 1993, Gustafson et al. 1993, Karch et al. 1994).

\section{BORRELIOSE EM ANIMAIS DOMÉSTICOS}

Os sintomas clínicos primários na borreliose canina envolvem síndrome musculoesquelética, invariável quanto a idade, raça ou sexo do animal, caracterizada pelo comprometimento de diversas articulações, principalmente carpiana e tarsiana, com quadro de artrite progressiva (Lissman et al. 1984, Levy \& Dreesen 1992); adicionalmente observa-se febre, letargia, inapetência e dor articular (Kornblatt et al. 1985, Magnarelli et al. 1985, Levy \& Magnarelli 1992). O animal apresenta claudicação, com dificuldade de apoiar o membro ao solo; pode ocorrer eritema no sítio da picada do carrapato (Appel 1990). Há relatos de vômito, dor abdominal e aborto, embora isso não seja comum (Azuma et al. 1994). Podem ocorrer cardiopatias com bloqueio átrio-ventricular e alteração de ritmo cardíaco (Levy \& Dreesen 1992, Azuma et al. 1994, Mckenna et al.1995). Comprometimento neurológico tem sido reportado em infecções naturais e experimentais por $B$. burgdorferi; e quadro de meningite por $B$. burgdorferi em cães foi descrito na Europa (Azuma et al. 1994, Mckenna et al. 1995). Anemia progressiva pode se instalar devido à característica hemolizante da borrélia, tal fenômeno foi comprovado, in vitro, por Williams \& Austin (1992).

Histologicamente a musculatura cardíaca mostra infiltrado inflamatório misto com neutrófilos e linfócitos, e fragmentos de espiroqueta (Levy \& Duray 1988, Cerri et al. 1994). Pode ocorrer nefrite, associada a proteinúria, azotemia, cilindrúria, piúria e hematúria; acarretando assim nefropatia severa, onde histologicamente observa-se aumento glomerular, adesão da cápsula de Bowman, proliferação mesangial, fibrose pericapsular, com focos de degeneração e necrose (Grauer et al. 1988). Pela imunofluorescência do tecido é possível observar a borrélia no interstício renal (Burgess et al. 1986a, Grauer et al. 1988). No cão como no homem, pode 
Quadro 1. Grupos de borrelioses: espécie(s) de patógeno(s) envolvido(s), vetor(es), hospedeiro(s) e distribuição

\begin{tabular}{|c|c|c|c|c|}
\hline Doença & Borrelia spp. & Vetor & Hospedeiros & Distribuição \\
\hline \multirow[t]{22}{*}{ Febre recurrente } & B. armenica & Ornithodoros sonrai & Homem & Ásia, Europa \\
\hline & B. brasiliensis & O. brasiliensis & Homem e roedores & América do Sul \\
\hline & B. caucasica & O. verrucosus & Homem e roedores & Ásia \\
\hline & B. crocidurae & O. erraticus & Homem e roedores & África e Ásia \\
\hline & B. dipodilli & O. marrocanus & Homem & Ásia e Europa \\
\hline & B. dugesii & O. dugesi & Homem e roedores & México \\
\hline & B. duttonii & 0. moubata & Homem & África \\
\hline & B. graingeri & O. graingeri & Homem e roedores & África \\
\hline & B. harveyi & Ornithodorus sp. & Macacos & África \\
\hline & B. hermsii & O. hermsii & Homem e roedores & América do Norte \\
\hline & B. hispanica & O. erraticus & Homem e roedores & Ásia e Europa \\
\hline & B. latyschevii & O. tartakovskyi & Homem, roedores e répteis & Ásia \\
\hline & B. mazzottii & O. talaje & Homem, roedores e macacos & México e Guatemala \\
\hline & B. merionesi & O. erraticus & Homem & África \\
\hline & B. microti & O. erraticus & Homem & África e Europa \\
\hline & B. parkeri & O. parkeri & Homem e roedores & Estados Unidos da América \\
\hline & B. persica & O. tholozani & Homem, roedor e morcegos & Ásia \\
\hline & B. queenslandica & O. gurneyi & Homem e roedores & Austrália \\
\hline & B. recurrentis & Pediculus humanus & Homem & Ásia, Am. do Norte, África e Europa \\
\hline & B. tillae & O. zumpti & Homem e roedores & África \\
\hline & B. turicata & O. turicatae & Homem e roedores & América do Norte \\
\hline & B. venezuelensis & O. rudis & Homem e roedores & América do Sul e Central \\
\hline \multirow[t]{2}{*}{ Borreliose aviária } & B. anserina & Argas (Argas) sp. ${ }^{\mathrm{a}}$ & galiformes, anatideos, & Cosmopolita \\
\hline & & A.(Persicargas) sp. $^{\mathrm{a}}$ & columbiformes e passeriformes & \\
\hline Borreliose bovina & B. theileri & $\begin{array}{l}\text { Boophilus sp. } \\
\text { Rhipicephalus sp. }\end{array}$ & Bovinos, ovinos e eqüinos & Cosmopolita \\
\hline \multirow[t]{10}{*}{ Borreliose de Lyme } & B. burgdorferi & $\begin{array}{l}\text { Ixodes sp. } \\
\text { Amblyomma americanum }\end{array}$ & $\begin{array}{l}\text { Homem, roedores, } \\
\text { cervídeos, cães, bovinos, } \\
\text { eqüinos, animais silvestres }\end{array}$ & $\begin{array}{l}\text { América do Norte e do Sul, } \\
\text { Europa, Ásia, África, } \\
\text { Austrália, }\end{array}$ \\
\hline & B. garinii & Ixodes sp. ${ }^{\mathrm{b}}$ & Homem, animais silvestres & Ásia, Europa \\
\hline & B. afzelii & Ixodes sp. ${ }^{\mathrm{b}}$ & Homem, animais silvestres & Europa \\
\hline & B. japonica & Ixodes sp. ${ }^{\mathrm{b}}$ & Homem, animais silvestres & Japão \\
\hline & B. miyamotoi & Ixodes sp. ${ }^{\mathrm{b}}$ & Homem, animais silvestres & Ásia \\
\hline & B. andersoni & Ixodes sp. ${ }^{\mathrm{b}}$ & Homem & Estados Unidos da América \\
\hline & B. lonestari & A. americanum & Homem & Estados Unidos da América \\
\hline & B. lusitaniae & Ixodes sp. ${ }^{\mathrm{b}}$ & Homem & Europa \\
\hline & B. valaisiana & Ixodes sp. ${ }^{\mathrm{b}}$ & Homem & Europa \\
\hline & Genoespécie DN127 & Ixodes sp. ${ }^{\mathrm{b}}$ & Homem & Estados Unidos da América \\
\hline Aborto epizoótico bovino & B. coriaceae & O. coriaceus & Bovinos e cervídeos & América do Norte \\
\hline
\end{tabular}

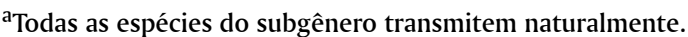

bAlgumas espécies do gênero transmitem naturalmente.

ocorrer glomerulonefrite com espaçamento glomerular, decorrido da deposição de imunocomplexos (Greene 1990, Duray 1993).

A primeira descrição de borreliose de Lyme em cães foi feita por Lissman et al. (1984) em um doberman de 3 anos de idade, que apresentava artrite carpiana severa, temperatura de $40,2^{\circ} \mathrm{C}$ e claudicação. $\mathrm{O}$ exame a fresco, pela microscopia de campo escuro e a cultura do líquido sinovial e do sangue, evidenciaram a presença de espiroquetas. A sorologia para deteç̧ão de anticorpos da classe IgG pela imunofluorescência, confirmou tratar-se de $B$. burgdorferi. Esse relato ocorreu em 1983 em New York, Estados Unidos, em uma área endêmica para a doença de Lyme. A partir deste relato deu-se maior importância à borreliose canina e de outros animais.

A maioria dos casos de borreliose em cães tem sido ocasionado por B. burgdorferi (Magnarelli et al. 1990a, Levy \&
Dressen 1992, Mather et al. 1994). Entretanto, Breitschwerdt et al. (1994) reportaram em dois cães da Flórida a infecção natural por Borrelia sp., a qual possuía homologia antigênica com $B$. burgdorferi; estudos moleculares comparando-a com $B$. burgdorferi, $B$. coriaceae e $B$. hermsii revelaram tratar-se de outra espécie. Os autores demonstraram a espiroqueta na circulação, mas não a nominaram, chamando-a, provisoriamente, de "Borrelia Canina da Flórida" (FCB). Mais tarde, outros pesquisadores isolaram e caracterizaram, a partir do carrapato $A$. americanum uma borrélia que possui posição filogenética próxima à "FCB" e a $B$. miyamotoi; essa mais nova espécie foi denominada $B$. lonestari Barbour, Maupin, Teltow, Carter \& Piesman, 1996 (Barbour et al. 1996).

A transmissão de B. burgdorferi "lato sensu", para os cães, ocorre pela picada de carrapatos infectados, sendo o gênero Ixodes, com as espécies I. scapularis, I. persulcatus, I. pacificus e 
I. ricinus, o mais importantes epidemiologicamente, porém Dermacentor variabilis e $A$. americanum também transmitem (Mather et al. 1994). A transmissão no cão pode ocorrer de forma intra-uterina, o que foi demonstrado experimentalmente com B. burgdorferi em cães beagle (Gustafson et al. 1993).

Na doença de Lyme, o cão pode atuar como importante sentinela epidemiológica, albergando a espiroqueta, comportando-se como reservatório no ambiente domiciliar, favorecendo, assim, ao carrapato veicular o patógeno até o homem e outros animais (Appel 1990, Bosler 1993, Mather et al. 1994). Esta enfermidade em cães está descrita na América do Norte, na Europa e na Ásia (Appel et al. 1993, Azuma et al. 1994, Cerri et al. 1994, Mckenna et al. 1995).

Embora ocorra apresentação clínica, o diagnóstico deve ser estabelecido e confirmado com o auxílio de ensaios imunológicos (Levy \& Magnarelli 1992, Jobe et al. 1994, Soares 1998). Diversas técnicas têm sido usadas, a imunofluorescência não confere bons resultados devido a reações cruzadas altas (Baker-Zander \& Lukerhart 1984, Frank 1989, Greene et al. 1989, Appel 1990); o ensaio imunoenzimático ELISA indireto e o western blotting são os mais utilizados por serem mais sensíveis e específicos (Magnarelli et al. 1987, Greene et al. 1988, Greene 1990, Engstrom et al. 1995, Ma et al. 1995). Técnicas mais precisas e modernas têm sido utilizadas, como a captura de antígeno e a reação de polimerase em cadeia (PCR), porém não são rotina devido ao custo e pouca praticidade, embora sejam as que se obtém os melhores resultados (Doward et al. 1991, Rasiah et al. 1994, Oksi et al. 1995, Mouritsen et al. 1996). Deve-se portanto, associar a clínica, o histórico, a sorologia e os dados epidemiológicos para se definir o diagnóstico, como realizado em humanos (Golightly 1993, Yoshinari et al. 1995, 1997).

A terapêutica se dá através de antibióticos; as tetraciclinas são eficientes, porém restritas a animais adultos. Penicilina, ampicilina e amoxicilina são efetivas por possuírem melhor absorção, mas a doxicilina é a mais indicada devido à sua característica lipoprotéica, que confere maior penetração no tecido (Appel 1990, Levy \& Dreesen 1992). Existem vacinas comerciais para cães com bacterinas íntegras ou "completas" (Chu et al. 1992), vacinas com subunidades de proteínas, contendo, principalmente, as proteínas de superfície OspA, OspB, OspC e outras (Coughlin et al. 1995, Fingerle et al. 1995, Ma et al. 1995) e vacinas com proteínas recombinantes (Jobe et al. 1994, Bennett 1995, Silva \& Fikrig 1997).

Há poucos estudos de borreliose em felinos; a espiroqueta relacionada a Felis catus é B. burgdorferi, sendo sua incidência, mesmo em áreas enzoóticas, muito baixa (Appel 1990, Magnarelli et al. 1990a). Acredita-se que os felinos sejam mais resistentes à borrélia; os poucos sinais clínicos relatados são brandos (Appel 1990, Burgess 1992). Mesmo em infecções experimentais, o animal não desenvolve sintomas aparentes e, pelo estudo histopatológico, não se observam alterações dignas de nota (Burgess 1992). Sabe-se que os animais são susceptíveis à infecção, e a soroprevalência é menor que nos cães. Estudos conduzido por Magnarelli et al. (1990b) e por Burgess (1992), através do teste ELISA indireto, demostraram a soroprevalência de 20 a 35\% em áreas onde há o parasitismo por I. scapularis.
A primeira observação de espiroquetas no sangue de ruminantes foi registrada por Arnold Theiler em 1902, na África do Sul, ao pesquisar a etiologia do "mal da bile" ou anaplasmose (Callow 1967). O agente descrito originalmente como Spirochaeta theileri, recebeu a posterior nominação de B. theileri Laveran, 1903. Esta espécie foi observada em bovinos, ovinos, eqüinos, cervídeos, ímpala e outros ruminantes silvestres (Irvin et al. 1973, Wouda et al. 1975, Matton \& Melckebeke 1990) como causa de anemia moderada, porém quando associada a outros hematozoários, pode produz doença grave (Irvin et al. 1973, Smith et al. 1985, Koch et al. 1990).

A espiroquetose dos ruminantes tem distribuição cosmopolita, ocorrendo em todas as regiões onde há seus potenciais transmissores (Neitz 1956, Callow 1967, Vivas et al. 1996). Os vetores são carrapatos do gênero Boophilus e as espécies Rhipicephalus evertsi e R. appendiculatus (Neitz 1956, Smith et al. 1985, Koch et al. 1990, Quinn et al. 1994), podendo ser essa borrélia patogênica para o carrapato, como relatado para B. microplus (Smith et al. 1978, Vivas et al. 1996).

Outra espiroqueta que acomete os ruminantes é $B$. burgdorefi "lato sensu", com registros de apresentação clínica em bovinos como aumento de volume articular, mialgia, febre, laminite, queda de produção e aborto (Rothwell et al. 1989, Parker \& White 1992, Wells et al. 1993). Outro sinal recentemente detectado é a ocorrência de dermatite digital ocasionada por B. burgdorferi; estudos na Europa (Blowey et al. 1994, Grund et al. 1995) e na América do Norte implicam a espiroqueta como causa de uma dermatite digital sem etiologia conhecida (Blowey et al. 1992). Em ovinos também há o registro desta espiroqueta, porém sem sinais de doença (Ogden et al. 1994). A borreliose de Lyme em ruminantes tem sido assinalada na América do Norte, na Europa e os estudos soroepidemiológicos demonstram que animais positivos, em sua maioria, são assintomáticos (Benxiu \& Collins 1994, Ishikawa 1996). A soroprevalência nos Estados Unidos da América pode chegar a 66\% (Benxiu et al. 1994) e estudos no Brasil revelaram positividade acima de 50\% (Fonseca et al. 1995b, 1996, Ishikawa 1996). O diagnóstico sorológico deve ser interpretado em conjunto com os dados epidemiológicos, sendo os ensaios ELISA indireto e western blotting os mais indicados (Benxiu et al. 1994, Fonseca et al. 1996, Ishikawa 1996, Ishikawa et al. 1997).

Embora infecte equiinos, $B$. theileri é considerada pouco patogênica para estes animais, exceto quando associada a piroplasmídeos (Quinn et al. 1994); a borreliose de Lyme, entretanto, causa sinais clínicos de perda de peso, claudicação esporádica, laminite, febre, aumento articular, enrijecimento muscular, uveíte anterior e sinais neurológicos como depressão, mudança de comportamento, disfagia, balanço de cabeça e encefalite (Cohen \& Cohen 1990, Parker \& White 1992). Artrite e panuveíte têm sido relatados em animais com idade avançada (Burgess et al. 1986b, Madigan 1993). A doença de Lyme em eqüinos só está bem definida nos Estados Unidos da América, e sua epidemiologia demonstra positividade de $12 \%$ a $75 \%$ entre animais assintomáticos (Marcus et al. 1985, Bernard et al. 1990, Parker \& White 1992). O diagnóstico é 
feito através do ensaio ELISA indireto pela pesquisa de anticorpos da classe $\operatorname{IgG}$, por ser esse mais eficiente (Magnarelli \& Anderson 1989, Bernard et al. 1990, Cohen et al. 1992). Não há registros em outros continentes.

A borreliose mais recentemente descrita é o aborto epizoótico bovino, enfermidade causada por B. coriaceae, agente que acomete bovinos e cervídeos (Quinn et al. 1994, Zingg \& Lefebvre 1994). Durante muitos anos essa doença teve sua etiologia desconhecida, tendo sido relacionada a vírus, a clamídia e a outras bactérias, até que se observou espiroquetose congênita em bezerros (Oselbold et al. 1986) e se isolou espiroqueta de carrapatos Ornithodorus coriaceus em áreas onde ocorria aborto epizoótico (Lane et al. 1985). Em 1987, caracterizou-se então B. coriaceae, definindo seu vetor e enfermidade (Johnson et al. 1987), posteriormente estudos imunológicos e epidemiológicos elucidaram o ciclo (Zingg \& Lefebvre 1994). No carrapato esta borrélia realiza a transmissão transovariana e transestadial (Lane \& Manweiler 1988).

A borreliose aviária é uma enfermidade septicêmica de caráter agudo ou subagudo, cujo quadro caracteriza-se por depressão, anorexia, febre, cianose de mucosas, diarréia e anemia severa. Pode ocorrer paralisia das pernas e a mortalidade varia de 10 a $99 \%$ de acordo à cepa, enquanto a morbidade é maior que 80\% (Hoogstraal 1985, Quinn et al. 1994). Tem como agente $B$. anserina que é transmitida por carrapatos do gênero Argas pertencentes aos subgêneros $A$. (Persicargas) e A. (Argas) (Diab \& Soliman 1977, Hoogstraal $1979,1985)$. Esta espiroqueta acomete as aves dos grupos dos galiformes, anatídeos, passeriformes, columbiformes e algumas aves silvestres (Wouda et al. 1975, Quinn et al. 1994). A enfermidade foi responsável por grandes mortalidades em aves de criações rústicas, tendo sua incidência diminuído com o uso de antibióticos nas rações. Tentativas de vacinas foram feitas, mas sem sucesso (Wouda et al. 1975).

\section{BORRELIOSE EM ANIMAIS SILVESTRES}

As aves silvestres têm papel relevante na epidemiologia da borreliose de Lyme (Anderson et al. 1986, Anderson 1988), pois estas servem de reservatórios para B. burgdorferi "lato sensu" (Olsen et al. 1995). A participação maior é das aves migratórias que transportam carrapatos infectados de uma região para outra (Battaly \& Fish 1993, Schoeler \& Lane 1993, Hubalek et al. 1996). Não há registros de doença nas aves ocasionada por esta espiroqueta, acredita-se que a elevada temperatura corpórea seja deletéria ou haja incompatibilidade imunológica bloqueando a ação patogênica da borrélia na ave (Manweiler et al. 1990, Nichols \& Callister 1996, Silva \& Fikrig 1997). O envolvimento das aves silvestres na epidemiologia da borreliose de Lyme está registrado na América do Norte (Manweiler et al. 1990, Battaly \& Fish 1993, Stafford et al. 1995, Nichols \& Callister 1996), na Europa (Matuschka \& Spielman 1992, Garcia-Monco 1993, Randolph \& Craine 1995) e na Ásia (Miyamoto et al. 1993, Nakao et al. 1994, Hubalek et al. 1996).

A borreliose de Lyme acomete cervídeos, embora raramente estes adoeçam. Os cervídeos atuam como reservatóri- os de Borrelia sp. mantendo a espiroqueta no ambiente silvestre (Steere et al. 1983, Steere 1989, Coyle 1993, Magnarelli et al. 1995a). Na América do Norte, o veado da cauda branca (Odocoileus virginianus) é o principal reservatório (Bosler 1993, Magnarelli et al. 1995a,b), embora outras espécies possam atuar como o Cervus nippon yesoensis (Kimura et al. 1995). Portanto, os cervídeos são sentinelas epidemiológicas nesta enfermidade (Gill et al. 1994).

Os roedores também possuem um estreito relacionamento com os microrganismos do gênero Borrelia, atuando como principais reservatórios e carreadores de $B$. recurrentis lato sensu (Quadro 1), transportando-a do ambiente silvestre ao peridomiciliar (Brumpt 1927, Pavlovsky 1965, Barbour \& Hayes 1986), porém dificilmente adoecem. As espécies do grupo $B$. burgdorferi "lato sensu", na sua maioria, são mantidas na natureza pelos roedores silvestres (Burgess et al. 1986a, Masuzawa et al. 1995, Jaenson \& Talleklint 1996). O roedor da pata branca (Peromyscus leucopus) e outros membros do gênero são os reservatórios naturais de B. burgdorferi "lato sensu" na América do Norte (Anderson et al. 1987, Lane et al. 1994, Lord et al. 1994, Maupin et al. 1994, Walker et al. 1996). Na Europa os roedores envolvidos pertencem, principalmente, ao gênero Apodemus (Kurtenbach et al. 1995), na Ásia, tanto o gênero Apodemus, quanto o gênero Eothenomys têm participação no ciclo da borreliose de Lyme (Masuzawa et al. 1995).

Os roedores têm sido utilizados como modelos para bioensaios com borrélias (Masuzawa et al. 1992, Pachner et al. 1995). Foram realizados experimentos com carrapatos avaliando-se potencial de transmissão, patogenicidade de cepas, ultramicroscopia de tecido infectado, desenvolvimento de vacinas, ensaios com drogas e expressão genética de Borrelia sp. (Shih \& Spielman 1993, Jobe et al. 1994, Pachner et al. 1995, Silva \& Fikrig 1997).

Outros animais silvestres como carnívoros, marsupiais e lagomorfos podem albergar Borrelia spp. no sangue e/ou nos tecidos, entretanto a sua participação no ciclo epidemiológico das borrelioses é discutível (Benach et al. 1987, Mclean et al. 1993, Isogai et al. 1994, Magnarelli et al. 1995c). No Brasil, estudos demonstram que os marsupiais podem participar na epidemiologia da doença de Lyme (Yoshinari et al. 1995, 1997, Battesti et al. 1997), uma vez que foram observadas espiroquetas com características morfológicas de Borrelia sp. em sangue periférico de Didelphis (marsupialis) aurita (Fonseca et al. 1995a, Abel 1996); estas espiroquetas eram infectantes para camundongos albinos (Barboza et al. 1998). As relações entre os marsupiais e esta espiroqueta está em discussão, embora ela tenha homologia antigênica, ao ELISA e western blotting, com B. burgdorferi (Fonseca et al. 1995a, Yoshinari et al. 1995, Bonoldi et al. 1996).

\section{DOENÇA DE LYME: A ZOONOSE DA DÉCADA}

Em 1883, o médico Buchwald descreveu na Alemanha uma atrofia difusa de pele com caráter idiopático, que em 1902 foi denominada acrodermatite atrófica crônica, embora a causa fosse desconhecida (Herxheimer \& Hartmann 1902). Anos depois, em 1910, Afzelius demonstrou que esta lesão 
estava associada à picada do carrapato Ixodes ricinus, referindo-a como eritema migratório; coube a Lipschutz, em 1913, introduzir o termo eritema migratório crônico, pela lesão manifestar-se durante mais de sete meses (Burgdorfer 1993). Afzelius associou à picada do carrapato a transmissão de vírus ou toxinas, mas Lipschutz descartou a hipótese de toxinas, aceitando que o eritema estava associado à patógenos, sugerindo então a pesquisa de microrganismos no trato digestivo dos carrapatos (Lipschutz 1913).

Associação do eritema com quadro neurológico foi relatado por Garin \& Bujadoux, em 1922, em pacientes com meningorradiculite e histórico de picada por I. hexagonus, condição diagnosticada como paralisia por carrapato. Contudo em 1930, Hellerstrom denominou a doença como a síndrome neurológica de Bannwerth, enquanto Garin \& Bujadoux sugeriram, posteriormente, que a condição poderia ter sido ocasionada por uma espiroqueta. A causa do eritema migratório crônico ficou em aberto, até que Hellerstrom (1950) relatou a associação do eritema com meningite e observou que sintomas de ordem meningocerebroespinhal ocorriam após picadas de carrapatos, e que podiam ser revertidos com penicilina, o que reforça a hipótese de ser uma espiroqueta transmitida pelo carrapato I. ricinus. Naquele tempo, porém, nunca fora reportada a presença de espiroquetas em ixodídeos.

Ainda na Europa, Binder et al. (1955) realizaram transplantes de pele afetada pelo eritema para pessoas sadias e observaram tratar-se de uma doença infecciosa, sendo o agente susceptível à penicilina. Outros pesquisadores associaram os sinais neurológicos à vírus, mas as encefalites virais não regridem ante a antibióticos, o que levou a aceitação de que a doença era causada por bactéria. Não pensava-se, todavia, em espiroquetas, de vez que pelos conhecimentos da época, elas só seriam transmitidas por argasídeos; além disso a observação de tecidos de carrapatos em campo escuro, bem como experimentos de transmissão resultaram negativos (Hard 1966).

Pesquisadores franceses sugeriram tratar-se de rickettsias, pois alguns pacientes reagiam à aglutinação para Rickettsia prowazekii, porém, a utilização de testes de fixação de complemento e de imunofluorescência também foram negativos (Burgdorfer 1993).

Nos Estados Unidos da América, o primeiro caso de eritema migratório crônico foi reportado em 1969 em um clínico que havia sido picado por carrapatos em Wisconsin. Posteriormente, quatro novos casos foram relatados em Connecticut em 1975, mas os pacientes não recordavam terem sido picados por artrópodes (Mast \& Burrows 1976). Mais tarde ocorreu um episódio de artrite associada ao eritema migratório, em Old Lyme, inicialmente, em duas pacientes, Polly Murray e Judith Mensch, depois em familiares e em pessoas de vilarejos próximos (Lyme e East Haddam, Connecticut), as quais queixavam-se de severa cefaléia, lesão de pele, artrite e sintomas neurológicos, o que sugeria tratar-se de artrite reumatóide juvenil. Foi então que o Departamento de Saúde de Connecticut solicitou auxílio ao Dr. Allan Steere, Reumatologista da Yale University Medical School. Steere re- alizou um estudo retrospectivo em 51 pacientes e verificou que a artrite poderia estar associada ao eritema; procedendo um inquérito sorológico contra 216 arboviroses, das quais 38 transmitidas por carrapatos, e testes para rickettsias; todos resultaram negativos. Pesquisou-se vírus no carrapato $I$. dammini, também sem sucesso (Steere et al. 1977a, Wallis et al. 1978). Assim, Steere denominou à enfermidade de artrite de Lyme ou doença de Lyme, uma desordem multisistêmica de agente desconhecido (Steere et al. 1977b).

Entre setembro e outubro de 1981 Jorge Benach coletou I. dammini em Nova York numa área endêmica para a doença de Lyme, para estudo de $R$. montana. Ao examinar a hemolinfa dos carrapatos, duas fêmeas estavam parasitadas por microfilárias de Dipetalonema rugosicauda, parasito natural de cervídeos. Para averiguar presença do filarídeo no trato digestivo dos carrapatos, Willy Burgdorfer dissecou-os e preparou lâminas coradas pelo Giemsa; não tendo observado microfilárias, mas estruturas semelhantes a espiroquetas; e ao observar tecido intestinal em campo escuro certificou tratar-se de espiroquetas. Ao examinar 124 carrapatos, $60 \%$ continham espiroquetas no trato digestivo (Burgdorfer et al. 1982). O material do intestino dos carrapatos, foi semeado em meio de Stoenner, acrescido ao meio de Kelly, para cultivo de $B$. hermsii e, após cinco dias, observou-se crescimento de espiroqueta, a qual foi designada como cepa B31 (Barbour 1984). Burgdorfer reexaminou esfregaços de intestino de $I$. ricinus, corados pelo Giemsa, coletados na Suíça, encontrando espiroquetas similares às de I. dammini (Burgdorfer et al. 1983). Sucessivamente foram demonstrados espiroquetas em lesões de pele e isoladas a partir de sangue de pacientes (Benach et al. 1983, Berger et al. 1983, Steere et al. 1983).

Em 1984, Ackermann obteve sucesso no tratamento do eritema migratório crônico com penicilina e tetraciclina, porém houve recidiva da lesão. Através de imunofluorescência, os autores demonstraram espiroquetas em I. ricinus nas duas áreas onde foram descritos os casos de eritema, na Alemanha (Ackermann 1984).

Após estudos, a espiroqueta B31 foi caracterizada e denominada Borrelia burgdorferi (Johnson et al. 1984) e, a partir daí, iniciou-se uma intensa pesquisa sobre a doença de Lyme, casos de eritema migratório, artrites e distúrbios neurológicos associados à picada de carrapatos, os quais foram revistos; aprofundaram-se os estudos clínicos caracterizando os sintomas e sistemas envolvidos (Steere 1989, Coyle 1993, Bennett 1995). Foram ainda definidos os envolvimentos dermatológico, nervoso, articular, cardíaco, renal e oftálmico, da enfermidade (Steere et al. 1983, Pachner \& Steere 1984, Garcia-Monco et al. 1990, Weber \& Pfister 1994).

Com base no vetor (I. dammini), procedeu-se o estudo epidemiológico que caracterizou os reservatórios na natureza, o cervídeo Odocoileus Virginianus e o roedor Peromyscus leucopus (Jaenson 1991, Lane et al. 1991, Bosler 1993). Diversas pesquisas foram desenvolvidas sobre a epidemiologia, controle, tratamento, interação borrélia-vetor, imunologia, vacinas, diagnóstico e lesões provocadas pelo patógeno (Coyle 1993, Telford et al. 1993, Bennett 1995, Schwan 1996, Silva \& Fikrig 1997). 
No início da década de 90 estabeleceram-se as diferenças de espectros clínicos da enfermidade nos diferentes continentes (Pfister et al. 1994, Euzeby 1995). Baranton et al. (1992) descreveram B. garinii, responsável por sintomas predominantemente neurológicos em pacientes europeus, e mais tarde também no Japão. Em seguida, ainda na Europa, foi revelado que a acrodermatite atrófica crônica tem como agente $B$. afzelii, que grassa ainda na Rússia e no Japão (Canica et al. 1993). As descobertas continuaram e no Japão em 1993, descreveu-se $B$. japonica, considerada pouco patogênica para o homem (Kawabata et al. 1993). No ano de 1993 outra espécie causadora da doença de Lyme foi revelada no Japão, $B$. miyamotoi (Postic et al. 1993).

Dois anos depois a genoespécie 21038 com características filogenéticas próximas a $B$. afzelii, foi descrita nos Estados Unidos da América como $B$. andersoni (Marconi et al. 1995). No ano seguinte Barbour et al. (1996) descreveram uma borrélia, inicialmente considerada não-cultivável, isolada do carrapato Amblyomma americanum; essa bactéria foi denominada $B$. lonestari, com posição filogenética próxima à B. burgdorferi. Em 1997, foi descrita na Europa B. lusitaniae (Le Fleche et al. 1997) e a B. valaisiana (Wang et al. 1997), todas agentes do "complexo borreliose de Lyme".

Assim passou-se a denominar à primeira espécie descrita como $B$. burgdorferi "stricto sensu" $\mathrm{e}$, as demais do grupo dessa enfermidade como pertencente ao complexo $B$. burgdorferi "lato sensu", estando os isolados não denominados dentro deste complexo, mas sendo a princípio denominado de genoespécie (Baranton et al. 1992, Euzeby 1995). Existe ainda um isolado causando doença do "complexo Lyme" nos Estados Unidos da América, a genoespécie DN127.

Para as borrelioses do "complexo Lyme" pode-se inferir que possuem caráter epidemiológico cosmopolita, sendo descrita na América do Norte, América Central, América do Sul, Ásia, África, Europa e Austrália. Embora ocorram manifestações clínicas muitas vezes distintas, todos agentes são transmitidos por carrapatos da família Ixodidae e são pertencentes ao gênero Borrelia (Kantor 1994, Bennett 1995, Barbour et al. 1996).

Na América do Sul esta enfermidade foi descrita na Argentina (Stanchi \& Balague 1993), na Bolívia (Ciceroni et al. 1994) e no Brasil (Filgueira et al. 1989, Azulay et al. 1991, Talhari et al. 1992, Barros et al. 1993, Yoshinari et al. 1993a, Costa et al. 1996). O primeiro relato da doença de Lyme no Brasil foi realizado por Filgueira et al. (1989) em pacientes com quadro dermatológico; posteriormente Azulay et al. (1991) também no Rio de Janeiro, e Talhari et al. (1992) em Manaus, relataram casos da doença associada a manifestações cutâneas.

Em 1989, Yoshinari e colaboradores alertam à classe médica para a possibilidade da existência desta enfermidade no Brasil. Estes autores fizeram uma revisão epidemiológica da doença no país (Yoshinari et al. 1992) e, em 1993 relataram o eritema migratório em uma paciente de São Paulo (Yoshinari et al. 1993a); na mesma época outro caso de acometimento cutâneo foi descrito juntamente com o tratamento (Barros et al. 1993). Ainda em 1993 mais cinco casos foram reportados
(Yoshinari et al. 1993b). A borreliose de Lyme foi então caracterizada como zoonose emergente no país e de interesse multidisciplinar, e os autores relatam e discutiram 25 casos clínicos e a epidemiologia da doença (Yoshinari et al. 1995). $\mathrm{O}$ primeiro caso com meningite foi descrito no Estado do Mato Grosso do Sul; no mesmo trabalho mais três casos foram reportados (Costa et al. 1996).

Em relação aos animais, os estudos iniciaram-se no Brasil com o relato da ocorrência de anticorpos contra Borrelia burgdorferi "lato sensu" em bovinos e com a detecção de antígenos circulantes em cães no Rio de Janeiro em 1994 (Fonseca et al. 1994). Posteriormente foi detectada Borrelia sp. em marsupiais (Fonseca et al. 1995a). Em São Paulo, Joppert (1995) relatou pelo método ELISA indireto soroprevalência de $9,7 \%$ em cães de uma área onde casos humanos foram descritos, enquanto Soares (1998) reportou, em cães, a prevalência de $20 \%$ no Rio de Janeiro. Alta prevalência foi relatada em bovinos dos Estados de São Paulo, Rio de Janeiro e Espírito Santo (Fonseca et al. 1996, Ishikawa 1996). Ensaios diagnósticos foram desenvolvidos para humanos (Yoshinari et al. 1995), cães (Joppert 1995, Soares 1998), bovinos (Ishikawa 1996, Ishikawa et al. 1997) e marsupiais (Bonoldi et al. 1996, Battesti et al. 1997).

No Brasil, o perfil da borreliose de Lyme foi caracterizado através de estudos clínicos, sorológicos, epidemiológicos e de tratamento realizados em cães, bovinos, animais silvestres e carrapatos, havendo relatos de aproximadamente 30 casos em humanos (Yoshinari et al. 1997).

Atualmente é difícil de estimar o número de casos de borreliose de Lyme no mundo. Nos Estados Unidos da América entre 1991 e junho de 1996 foram registrados e catalogados 68.839 novos casos, sendo a enfermidade descrita em quase todo o país (CDC 1997). No Brasil, os estudos prosseguem, já que não foi caracterizada a espiroqueta responsável pela enfermidade, embora sabe-se que a espécie aqui existente, isolada de carrapatos e marsupiais, possui características antigênicas homólogas às de $B$. burgdorferi "stricto sensu", de B. garinii e de B. afzelii detectadas pelas técnicas de ELISA e western blotting (Yoshinari et al. 1995, 1997).

Passaram-se 116 anos da descoberta original da acrodermatite atrófica crônica por Buchwald em 1883 e, após a descoberta de $B$. burgdorferi "stricto sensu", as pesquisas sobre esse agente se intensificaram em todo o mundo. Nenhuma outra doença, depois da AIDS, foi estudada tão intensamente, com pesquisas multidisciplinares profundas e modernas; esta é a doença que foi objeto de maior número de publicações nos periódicos científicos de grande circulação nos últimos anos (Coyle 1993, Bennett 1995, CDC 1997), podendo ser a "zoonose da década".

\section{ASSOCIAÇÃO DE BORRÉLIA COM OUTROS HEMATOZOÁRIOS}

Os carrapatos são os artrópodes hematófagos responsáveis por transmitirem a maior diversidade de patógenos (Hoogstraal 1985, Soneshine 1991). Originalmente, a febre recurrente epidêmica foi descrita como sendo transmitida por anopluros, mais tarde observou-se que os carrapatos do 
gênero Ornithodorus eram os principais vetores da febre recurrente endêmica. Estes podem veicular $B$. recurrentis "lato sensu”, e diferentes espécies de Ornithodorus transmitem a mesma espécie de borrélia (Dodge 1973, Hoogstraal 1979, 1985, Barbour \& Hayes 1986). Associados ao agente da febre recurrente, carrapatos do gênero Ornithodorus, podem veicular Rickettsia spp. como a do tifo exantemático, e vários arbovírus (Brumpt 1927, Pavlovsky 1965, Hoogstraal 1985). Acredita-se que a associação de $B$. recurrentis, rickettsias e arbovírus, tenha levado a óbito milhares de pessoas na África e na Ásia entre os séculos XVII e XIX (Brumpt 1927, Pavlovsky 1965).

A descrição original do mais importante vetor de $B$. burgdorferi, o carrapato I. dammini, foi realizada concomitante ao relato de babesiose humana causada por Babesia microti (Spielman et al. 1979). Porém, em 1993, pesquisadores demonstraram que I. dammini é sinonímia de I. scapularis (Oliver $\mathrm{Jr}$ et al. 1993). Posteriormente outros trabalhos foram realizados discordando da sinonímia, e atualmente aceita-se que I. dammini é subespécie permanecendo então I. scapularis dammini (Telford et al. 1997).

Pelo estudo da ecologia de $I$. s. dammini verificou-se que esta espécie é o principal vetor de $B$. burgdorferi e $B$. microti (Spielman et al. 1985), ambos patógenos que acometem roedores e o homem (Piesman et al. 1986, Spach et al. 1993, Walker \& Dumler 1996); e muitos casos de babesiose humana foram descritos na América do Norte associados à doença de Lyme (Telford et al. 1997).

Outra enfermidade que vem sendo averiguada na sua relação com a borreliose de Lyme é a ehrlichiose humana (Spach et al. 1993, Magnarelli et al. 1995b); atualmente existem duas espécies descritas no homem, Ehrlichia chaffeensis que tem como principal vetor $A$. americanum, que também transmite Borrelia sp. (Anderson et al. 1993, Walker \& Dumler 1996, Telford et al. 1997), e a ehrlichia granulocítica humana, ainda não nomeada, cujo principal vetor é I. dammini, porém outros carrapatos também podem transmitir (Chen et al. 1994, Rikihisa et al. 1994, Yevich et al. 1995, Walker \& Dumler 1996).

Coexistência de anticorpos para babesiose humana, ehrlichiose e borreliose têm sido observada em soros de pacientes de áreas de risco para estas enfermidades, sem contudo haver necessariamente reações cruzadas (Magnarelli et al. 1995 a,b; Telford et al. 1997). Este fenômeno é pertinente pois o roedor $P$. leucopus é o reservatório de $B$. burgdorferi e de $B$. microti e, o cervídeo 0 . virginianus é o reservatório de $E$. chaffeensis, da ehrlichia granulocítica humana e de $B$. burgdorferi (Dawson et al. 1994, Dumler et al. 1995).

Recentemente, foi descrito um arbovírus causador de encefalite, transmitido por I. dammini e provisoriamente denominado "deer tick virus" (= vírus do carrapato de cervídeo), que acompanha a epidemiologia da doença de Lyme, da babesiose humana e da ehrlichiose granulocítica humana (Telford et al. 1997). A febre maculosa das Montanhas Rochosas, cujo agente é $R$. rickettsia e o principal vetor Dermacentor variabilis, também ocorre em áreas endêmicas para a borreliose de Lyme (Magnarelli et al. 1979).

No Brasil, tem sido relatada a ocorrência de febre maculosa em humanos, principalmente nos Estados de São Paulo, Rio de Janeiro e Espírito Santo, sendo o carrapato A. cajennense o principal transmissor e o cão um dos reservatórios (Sexton et al. 1993, Lemos et al. 1994). Coincidentemente, a maioria dos casos de borreliose de Lyme em humanos e bem como a presença de anticorpos em animais foram reportados nas mesmas regiões (Fonseca et al. 1995b, 1996, Yoshinari et al. 1995, 1997).

Nas aves, há relatos da ocorrência de $B$. anserina em conjunto com a rickettsia intraeritrocítica Aegyptinella pullorum, ambas transmitidas por Argas sp. (Brumpt 1927, Hoogstraal 1985). No Brasil, a descrição da malária neotropical das aves galliformes foi feita em 1941, quando os pesquisadores Versiani \& Gomes ao estudarem a borreliose aviária, observaram e descreveram, casualmente, Plasmodium juxtanucleare (Versiani \& Gomes 1941). A rickettsia intraeritrocítica das aves no Brasil é Neitziella rezendei descrita ao se pesquisar malária aviária (Massard et al. 1976).

Em cães, a associação de hematozoários é frequentemente observada, podendo encontrar-se concomitante Babesia canis, E. canis, Hepatozoon canis e Haemobartonella canis (Iqbal et al. 1994). Têm-se relatado ainda das associações entre E. canis e E. ewingii e/ou E. platys, e entre Ehrlichia sp., Babesia sp. e B. burgdorferi (Breitschwerdt et al. 1994, Rikihisa et al. 1994). Estas relações entre hematozoários são pertinentes, visto que muitas delas possuem o mesmo carrapato vetor, para cada região (Iqbal \& Rikihisa 1994, Eremeeva et al. 1995). Foi verificado, experimentalmente em cão, a ausência de interação imunológica entre anticorpos contra $B$. burgdorferi "stricto sensu" cepa G39/40 e infecção por B. canis (Soares 1998).

Em equiinos ocorre o parasitismo por Babesia equi, B. caballi, $E$. equi e $B$. theileri, estando esta associação na dependência da região fisiográfica e dos mesmos vetores; este fenômeno agrava o quadro clínico do animal (Callow 1967, Dumler et al.1995, Richter et al. 1996).

Borrelia theileri foi descrita em 1902 na África do Sul ao se pesquisar a anaplasmose bovina, cujo agente Anaplasma marginale só foi descrito posteriormente em 1910. Em 1959, na Argentina foi relatada em bovinos com babesiose, uma borrélia que denominaram $B$. najerai; posteriormente verificou-se que se tratava de $B$. theileri (Callow 1967). Nas regiões tropicais e subtropicais do globo, Boophilus microplus é o principal vetor da Babesia bigemina, de B. bovis e de Anaplasma marginale, sendo também para $B$. theileri (Neitz 1956, Smith et al. 1978).

A borreliose bovina determinada por B. theileri, geralmente ocorre associada à babesiose e/ou anaplasmose, vindo a agravar o quadro hematológico do animal, especialmente em animais esplenectomizados (Smith et al. 1985, Uilenberg 1986, Matton \& Melckebeke 1990). No Brasil, B. theileri foi relatada em bovinos ao se estudarem protófitas (rickettsias), em animais esplenectomizados (Lopes 1976). Na África observa-se borreliose associada à babesiose, theileriose, anaplasmose e eperitrozoonose (Koch et al. 1990).

Ruminantes silvestres, como os cervídeos, são reservatórios de diversos hematozoários que afetam animais domésticos e o homem, como Anaplasma sp., Babesia sp., Eperitro- 
zoon sp., Ehrlichia sp., Theileria sp., Trypanosoma sp. e Borrelia sp. (Dawson et al. 1994, Walker \& Dumler 1996). Em ímpalas Irvin et al. (1973) observaram o parasitismo conjunto por Theileria sp., Trypanosoma sp. e B. theileri.

Em estudo da ocorrência de Borrelia sp. no marsupial Didelphis marsupialis, no Rio de Janeiro, foi demonstrado o parasitismo mútuo de Borrelia sp. com o piroplasmídeo Babesia brasiliensis (Abel 1996).

\section{EPIDEMIOLOGIA SOROLÓGICA E DIAGNÓSTICA DE BORRELIOSE}

O diagnóstico de borreliose pode ser realizado em animais, através de esfregaços sanguineos periféricos, preferencialmente corados pelo Giemsa ou pelo método de Fontana, entretanto os agentes só são detectáveis em casos de alta espiroquetemia (Brumpt 1927, Pêssoa 1963, Matton \& Melckebeke 1990).

Esfregaços também podem ser feitos a partir de fragmento de tecidos do carrapato como intestino, glândula salivar e ainda hemolinfa, corados pelo Giemsa, método utilizado originalmente para a observação de $B$. burgdorferi e, muito utilizado no estudo de $B$. anserina e $B$. theileri no carrapato (Diab \& Soliman 1977, Smith et al. 1978, Burgdorfer et al. 1982, Vivas et al. 1996). No tecido de animais, as colorações argênticas oferecem boas visualizações. A habilidade na observação microscópica é importante dado o grande pleomorfismo das borrélias (Aberer \& Duray 1991).

Recuperação e isolamento podem ser feitos através de filtração em microfiltros de 0,20 a $0,45 \square \mathrm{m}$ (Jobe et al. 1993). No isolamento utiliza-se o meio de BSK, o meio de Kelly, o meio de Stoenner, ou similares, aos quais semeia-se sangue, fragmentos de tecidos ou de carrapatos, obtendo-se o crescimento da espiroqueta a $33^{\circ} \mathrm{C} \mathrm{em}$ aproximadamente sete dias (Kuiper et al. 1994, Lebech et al. 1995). O isolamento de borrélia tem sido realizado a partir de saliva, fragmentos de glândula salivar e intestino, dos carrapatos Ixodes scapularis, I. s. dammini, I. pacificus, I. persulcatus, I. ricinus, I. ovatus, A. americanum, Dermacentor variabilis e outros (Miyamoto et al. 1992, Nakao et al. 1992, Ewing et al. 1994, Takada et al. 1994, Talleklint \& Jaenson 1996).

A imunohistoquímica é um método que apresenta excelentes resultados já que permite a observação de borrélia, a caracterização microscópica da lesão e ainda revela marcações antigênicas do patógeno no tecido, entretanto, em humanos, tem-se a dificuldade da obtenção de fragmentos de tecidos, sendo esta técnica pouco utilizada (Lebech et al. 1995). A imunofluorescência é usada em tecidos de carrapatos para a observação de espiroquetas, entretanto esta técnica apresenta reação cruzada e inespecífica (Burgdorfer 1993). A técnica ELISA de captura foi utilizada em tecidos do carrapato I. dammini para a detecção de antígenos de $B$. burgdorferi com bons resultados, mesmo utilizando-se anticorpos policlonais (Dorward et al. 1991).

O método ELISA indireto tem sido amplamente utilizado para pesquisa de anticorpos anti-carrapatos em humanos de áreas de risco, ou onde ocorram enzootias de borreliose de
Lyme, babesiose humana e ehrlichiose humana; este método serve como suporte para o conhecimento epidemiológico das enfermidades, além de avaliar a interação do carrapato com o patógeno, através de anticorpos anti-saliva (Schwartz et al. 1990, 1993).

A imunofluorescência indireta é um ensaio subjetivo para ser empregado no diagnóstico de borrelioses, podendo ser utilizado para triagem ou, ocasionalmente, quando dados clínicos e epidemiológicos ajudam no diagnóstico (Bennett 1995). Embora Russell et al. (1984) tenham demonstrado igual sensibilidade e especificidade entre imunofluorescência e ELISA, a maioria dos estudos revelam a superioridade do ELISA indireto, em termos de sensibilidade, especificidade e operacionalidade (Stiernstedt et al. 1985, Golightly 1993). Magnarelli et al. (1984) reportam ao comparar a IF com ELISA em soros de cães ser o ELISA mais eficiente.

Em 1988, Magnarelli \& Anderson, desenvolveram ELISA indireto para detecção de anticorpos das classes IgG e IgM em humanos, observando ausência de reação cruzada heteróloga entre B. burgdorferi, Leptospira canicola, L. icterohaemorrhagiae, L. grippotyphosa e L. wolffi; houve apenas leve reação cruzada com Treponema sp., os autores concluem que o ensaio padronizado pode ser utilizado no diagnóstico da borreliose de Lyme e no diagnóstico diferencial com outras espiroquetoses.

No método ELISA indireto, borrélias íntegras, antígeno sonicado ou frações protéicas podem ser usado como antígeno, contudo os dois últimos preparados têm mostrado melhores resultados (Bennett 1995, Oksi et al. 1995), sendo o antígeno sonicado o mais empregado (Craft et al. 1984, Magnarelli et al. 1994a). O ensaio imunoenzimático para detecção de antígenos de borrélia ainda tem sido utilizado, através de captura em urina, sangue e soro de cães, humanos e roedores (Hyde et al. 1989, Doward et al. 1991), e por inibição em urina de roedores (Magnarelli et al. 1994b), todos com resultados confirmados.

$O$ western blotting tem sido empregado secundariamente como definição do resultado, em casos de dúvida no método ELISA. A problemática do imunoblotting é a obtenção do padrão positivo ideal ("gold standard") pelos laboratórios, o que se torna difícil, exceto em caso de imunizações experimentais (Engstrom et al. 1995, Sood et al. 1995). Em ensaios com soros humanos, para a doença de Lyme, Grodzicki $\&$ Steere (1988) demonstraram a superioridade do blotting sobre o ELISA, pois essa técnica é mais sensível e específica, podendo ser usada para confirmar o ELISA (Dressler et al. 1993).

Joppert (1995) e Fonseca et al. (1996) trabalhando, respectivamente, com soros de cães e de bovinos comprovaram a superioridade do imunoblotting. Contudo, este ensaio deve seguir critérios de interpretação, pois existem variações antigênicas regionais para a borrélia, além de espécies distintas e homólogas (Craft et al. 1986, Rahn \& Malawista 1991, Baranton et al. 1992, Sood et al. 1995), devendo-se, portanto, estabelecer qualidade de bandas reativas de acordo ao antígeno utilizado, para cada região estudada, e também 
quantidades de bandas, no mínimo de cinco (Steere 1989, Golightly 1993, Engstrom et al. 1995, Sood et al. 1995).

A técnica de reação em cadeia de polimerase (PCR) é o mais preciso dos ensaios, pois garante o resultado específico através da amplificação do DNA do agente. Esta técnica tem sido empregada em fluidos e tecidos de humanos e de animais, e em fragmentos de carrapatos (Lienbling et al. 1993, Moter et al. 1994, Zbinden et al. 1994), estando ainda relacionada às manifestações clínicas e respostas sorológicas (Lebech \& Hanse 1992, Karch et al. 1994, Mouritsen et al. 1996); a desvantagem é o custo muito oneroso.

Reações cruzadas têm sido descritas entre $B$. burgdorferi $\mathrm{e}$ L. interrogans, com algumas variantes sorológicas, entretanto estas reações ocorrem em alguns laboratórios e em outros não, dependendo do preparo do antígeno e do ensaio empregado (Mitchell et al. 1994). São freqüientes as reações cruzadas entre os membros do gênero Borrelia, principalmente nos bovinos (Donoghue \& Van Veen 1989). Muitas reações cruzadas são descritas no emprego de macrotécnicas, como a aglutinação, nos quais Borrelia sp. reage com Treponema sp. e com Leptospira sp. (Baker-Zander \& Lukerhart 1984). Para se evitarem estas reações entre antígenos heterólogos devemse ser feitos diluições seriadas altas (Meredith et al. 1995); mesmo havendo o parasitismo mútuo por Borrelia sp. e por outros hematozoários, como os protozoários e ricket-tsias, não ocorrem reações cruzadas, havendo sim a coexistência de anticorpos distintos, como foi comprovado em humanos por Magnarelli et al. (1995a).

Em todas as regiões onde se tem descrito a borreliose de Lyme, o ensaio ELISA indireto é utilizado para diagnóstico e levantamentos epidemiológicos (Kawabata et al. 1987, Steere 1989, Jaenson 1991, Golightly 1993). Em animais, estudos de soroprevalência de borreliose são feitos através do ELISA indireto com antígeno sonicado total ou suas frações (Benxiu et al. 1994, Soares 1998).

Na América do Norte, a soroprevalência da borreliose de Lyme em bovinos assintomáticos pode chegar a 75\% (Parker \& White 1992, Benxiu \& Collins 1994). No Japão está em torno de $25 \%$, como reportado por Takahashi et al. (1993) em uma população de 970 animais. Na Austrália, a prevalência não foi avaliada, pois há raros casos em animais (Rothwell et al. 1989). No Brasil, através do ELISA indireto, foi estimada em $72,51 \%$ a frequiência para anticorpos da classe $\operatorname{IgG}$, em bovinos assintomáticos da região sudeste, referindo-se os autores à exposição prévia a $B$. burgdorferi "lato sensu" (Fonseca et al. 1996). Ainda no Brasil, Ishikawa et al. (1997) padronizaram um ELISA indireto para bovinos, utilizando antígeno sonicado total de B. burgdorferi "stricto senso" cepa G39/40.

Nos Estados Unidos da América, os relatos indicam uma frequiência média entre 12 a $34 \%$ para eqüinos assintomáticos (Bernard et al. 1990, Cohen et al. 1992). Em cães, desde o primeiro relato de borreliose de Lyme nesta espécie (Lissman et al. 1984), tem-se utilizado o ELISA indireto no diagnóstico; a epidemiologia demonstra que, na América do Norte, a prevalência de cães reagentes por este ensaio, em áreas endêmicas pode ser superior a $50 \%$ em animais assintomáticos
(Greene 1990). No Japão, ao se estudarem sorologicamente 21 cães pelo ELISA, observaram-se 16 animais positivos $(76,19 \%)$ (Azuma et al. 1994).

O método ELISA indireto é empregado ainda para pesquisa em animais silvestres como roedores, cervídeos, marsupiais, carnívoros e aves; esse ensaio tem auxiliado no conhecimento epidemiológico das borrelioses, além de certificar animais sentinelas (Gill et al. 1994, Magnarelli et al. 1995a,b).

O diagnóstico seguro da borreliose implica na qualidade do ensaio. $O$ ensaio imunoenzimático ELISA indireto tem sido o mais empregado e reconhecido, no entanto deve ser estabelecido para cada laboratório com os padrões de controle adequados, com o título mínimo e linha de corte ("cut-off") seguros. Deve-se evitar, portanto, os kits comerciais para diagnóstico, em função das muitas reações cruzadas (Magnarelli 1989, Magnarelli \& Anderson 1989, Callister et al. 1990).

A epidemiologia das borrelioses em animais e no homem apresenta características variadas de acordo com as regiões dada a existência distinta de espécies, genoespécies e cepas de Borrelia, bem como de carrapatos vetores, de interações vetor-patógeno e de ecossistemas distintos (Baranton et al. 1992, Coyle 1993, Bennett 1995, Euzeby 1995, Yoshinari et al. 1997). Os animais domésticos são competentes reservatórios de Borrelia sp. no ambiente domiciliar (Mather et al. 1994), contudo fazem-se necessários estudos fisiográficos com o fim de se estabelecer a situação regional da enfermidade.

\section{REFERÊNCIAS}

Abel I.S. 1996. Estudo de Borrelia sp. em Didelphis marsupialis (Marsupialia: Didelphidae) naturalmente infectados. Trabalho de Monografia, Bacharel em Ciências Biológicas, Instituto de Biologia, UFRRJ, Rio de Janeiro. 40p.

Aberer E. \& Duray P.H. 1991. Morfology of Borrelia burgdorferi: structural patterns of cultured borreliae in relation to staining methods. J. Clin. Microbiol. 29(4):764-772.

Ackermann R. 1984. Spirochaeten-Aetiologie der Erythema chronicum migrans Krankheit. Dtsch. Med. Wochenschr. 109:2.

Afzelius A. 1910. Verhandlungen der Dermatologischen Gesellschaft zu Stockholm. Arch. Derm. Syph. 101: 04-406.

Anderson J.F., Johnson R.C., Magnarelli L.A. \& Hyde F.W. 1986. Involvement of birds in the epidemiology of Lyme disease agent Borrelia burgdorferi. Infect. Immun. 51:394-396.

Anderson J.F., Duray P.H. \& Magnarelli L.A. 1987. Prevalence of Borrelia burgdorferi in white-footed mice and Ixodes dammini at Fort McCoy, Wis. J. Clin. Microbiol. 25(8):1495-1497.

Anderson J.F. 1988. Mammalian and avian reservoirs for Borrelia burgdorferi. Ann. N. Y. Acad. Sci. 539:190.

Anderson B.E., Sims K.G., Olson J.G., Childs J.E., Piesman J.F., Happ C.M., Maupin G.O. \& Johnson B.J. 1993. Amblyomma americanum a potential vector of human ehrlichiosis. Am. J. Trop. Med. Hyg. 49(2):239-244.

Appel J.G. 1990. Lyme disease in dogs and cats. Compendium 12(5):617.

Appel M.J.G., Allan S., Jacobson R.H., Lauderdale T.L., Chang Y.F., Shin S.J., Thomford J.W., Todhunter R.J. \& Summers B.A. 1993. Experimental Lyme disease in dogs produces arthrits and persistent infection. J. Infect. Dis. 167:651-664.

Austin F.E.. 1993. Maintenance of infective Borrelia burgdorferi Sh-2-82 in 4\% oxygen - 5\% carbon dioxide in vitro. Can. J. Microbiol. 39:1103-1110.

Azulay R.D., Abulafia L., Sodre C.S., Azulay R.A. \& Azulay M.M. 1991. Lyme disease in Rio de Janeiro, Brazil. Int. J. Dermatol. 30:569-571. 
Azuma Y., Isogai E., Isogai H. \& Kawamura K. 1994. Canine Lyme disease: clinical and serological evaluations in 21 dogs in Japan. Vet. Rec. 134:369372 .

Baker-Zander S. \& Lukerhart S.A. 1984. Antigenic cross-reactivity between Treponema pallidum and other pathogenic members of the family Spirochaetaceae. Infect. Immun. 46(1):116-121.

Balashov Y.S. 1972. A translation of bloodsucking ticks (Ixodoidea)-vectros of diseases of man and animals. Misc. Publicat. Entomol. Soc. Am. 8(5):159376.

Baranton G., Postic D. \& Saint Giros I. 1992. Delineation of Borrelia burgdorferi sensu stricto, Borrelia garinii sp. nov., and VS461 associated with Lyme borreliosis. Int. J. Syst. Bacteriol. 42:378-83.

Barboza W.G.A., Almeida Jr D.E., Silva L.A.M. \& Fonseca A.H. 1998. Detecção de Borrelia sp. em gambás imunossuprimidos com ciclofosfamida. Revta Bras. Med. Vet. 20(6):241-243.

Barbour A.G. 1984. Isolation and cultivation of Lyme disease spirochetes. Yale J. Biol. Med. 57:521-525.

Barbour A.G. 1990. Antigenic variation of a relapsing fever Borrelia species. Annu. Rev. Microbiol. 44:155-171.

Barbour A.G., Burgdorfer W., Grunwaldt E. \& Steere A.C. 1983. Antibodies of patients with Lyme disease to components of the Ixodes dammini spirochete. J. Clin. Invest. 72:504-515.

Barbour A.G. \& Hayes S.F. 1986. Biology of Borrelia species. Microbiol. Rev. 50(4):381-400.

Barbour A.G., Maupin G.O., Teltow G.J., Carter C.J. \& Piesman J. 1996 Identification of an uncultivable Borrelia species in the hard tick Amblyomma americanum: possible agent of a Lyme disease-like illness. J. Infect. Dis. 173:403-409.

Barros P.J.L., Levy L.H., Monteiro F.G.V. \& Yoshinari N.H. 1993. Doença de Lyme: acometimento cutâneo e tratamento das fases iniciais. Revta Assoc. Med. Brasil. 39:170.

Battaly G.R. \& Fish D. 1993. Relative importance of bird as hosts for immature Ixodes dammini (Acari: Ixodidae) in a suburban residential landscape of southern New York State. J. Med. Entomol. 30(4):740-747.

Battesti D.M., Soares C.O., Zeitune A.D., Yoshinari N.H. \& Arzua M. 1997. Estudo de Didelphis marsupialis (Marsupialia: Didelphidae) como reservatório da borreliose de Lyme, através de método sorológico. XV Congr. Bras. Parasitol., p.252. (Resumo)

Benach J.L., Bosler E.M., Hanrahan J.P., Coleman J.H., Habicht G.S., Bast T.F., Cameron D.J., Ziegler J.L., Barbour A.G., Burgdorfer W., Edelman R. \& Kaslow R.A. 1983. Spirochetes Isolated from the blood of two patients with Lyme disease. New Engl. J. Med. 308:740.

Benach J.L., Coleman J.H., Skinner R.A. \& Bosler E.M. 1987. Adult Ixodes dammini on rabbits: a hypothesis for the development and transmission of Borrelia burgdorferi. J. Infec. Dis. 155(6):1300-1306.

Bennett C.E. 1995. Ticks and Lyme disease. Adv. Parasitol. 36:343-405.

Benxiu J. \& Collins M. 1994. Seroepidemilogic survey of Borrelia burgdorferi exposure of dairy cattle in Wisconsin. Am. J. Vet. Res. 55(9):1228-1231.

Benxiu J., Thomas C.B. \& Collins M.T. 1994. Evaluation of an enzyme-linked immunosorbent assay that uses the $41-\mathrm{kd}$ flagellin as the antigen for detection of antibodies to Borrelia burgdorferi in cattle. Am. J. Vet. Res. 55(9):1213-1219.

Berger B.W., Clemmenson O.J. \& Ackermann A.B. 1983. Lyme disease is a spirochetosis: a review of the disease and evidence of its cause. Am. J. Dermatopathol. 5:111.

Bernard W.V., Cohen D., Bosler E. \& Zamos D. 1990. Serologic survey for Borrelia burgdorferi antibody in horses referred to a mid-Atlantic veterinary teaching hospital. J. Am. Vet. Med. Assoc. 196(8):1255-1258.

Binder E., Doepfmer R. \& Hornstein O. 1955. Experimentelle Übertragung des Erythema chronicum migrans von Mensch zu Mensch. Hautarzt 6: 494497.

Blowey R.W., Sharp M.W. \& Done S.H. 1992. Digital dermatitis. Vet. Rec. 134:39. Blowey R.W., Carter S.D., White A.D. \& Barnes A. 1994. Borrelia burgdorferi infections in UK cattle: a possible association with digital dermatitis. Vet. Rec. 135:577-578.

Bonoldi V.L.N., Battesti D.M., Fonseca A.H., Soares C.O., Leon E.P., Zeitune A.D. \& Yoshinari N.H. 1996. Participação dos gambás (Didelphis marsupialis) no ciclo epidemiológico da doença de Lyme. Revta Bras. Reumatol. 36(5):276.

Bosler E.M. 1993. Tick vectors and hosts, p. 18-26. In: Coyle P.K (ed.) Lyme Disease. Mosby Year Book, Boston.

Bouseman J.K., Kitron U., Kirkpatrick C.E., Siegel J. \& Todd K.S. 1990. Status of Ixodes dammini (Acari: Ixodidae) in Illinois. J. Med. Entomol. 27(4):556560 .

Breitschwerdt E.B., Nicholson W.L., Kiehl A.R., Steers C., Meuten D.J. \& Levine J.F. 1994. Natural infections with Borrelia spirochetes in two dogs from Florida. J. Clin. Microbiol. 32(2):352-357.

Brumpt E. 1927. Précis de parasitologie, Collection de Précis Médicaux Masson \& C ie Éditeurs, Paris, p. 1452.

Buchwald A. 1883. Ein Fall von diffuser idiopathischer Hautatrophie. Derm. Vierteljahresschr. 10:553-554.

Burgdorfer W. 1956. The possible role of ticks as vectors of leptospirae. I. Transmission of Leptospira pomona by the argasid tick, Ornithodorus turicata, and the persistence of this organism in its tissues. Exp. Parasitol. 5:571579.

Burgdorfer W., Barbour A.G. \& Hayes S.F. 1982. Lyme disease: a tick-borne spiroquetosis? Science 216:1317-1319.

Burgdorfer W., Barbour A.G., Hayes S.F., Peter O. \& Aeschlimann A. 1983. Erythema chronicum migrans - tickborne spirochetosis. Acta Trop. 40:7983.

Burgdorfer W., Lane R.S., Barbour A.G., Gresbrink R.A. \& Anderson J.R. 1985. The western black-legged tick, Ixodes pacificus: a vector of Borrelia burgdorferi. Am. J. Med. Hyg. 34(5):925-930.

Burgdorfer W. 1993. Discovery of Borrelia burgdorferi, p. 3-7. In: Coyle P.K. (ed.) Lyme Disease. Mosby Year Book, Boston.

Burgess E.C., Amundson T.E., Davis J.P., Kaslow R.A. \& Edelman R. 1986a. Experimental inoculation of Peromyscus spp with Borrelia burgdorferi: evidence of contact transmission. Am. Soc. Trop. Med. Hyg. 35(2):355-359.

Burgess E.C., Gillette D. \& Pickett J.P. 1986b. Arthritis and panuveitis as manifestation of Borrelia burgdorferi infection in a Wisconsin pony. J. Am. Vet. Med. Assoc. 189(10):1340-1342.

Burgess E.C. 1992. Experimentally induced infection of cats with Borrelia burgdorferi. Am. J. Vet. Res. 53(9):1507-1511.

Burman N., Bergström S., Restrepo B.I. \& Barbour A.G. 1990. The variable antigens Vmp7 and Vmp21 of the relapsing fever bacterium Borrelia hermsii are structurally analogous to the VSG proteins of the african trypanosome. Mol. Microbiol. 4:1715-1726.

Butler J.F. \& Denmark H.A. 1990. Tick (Acari: Ixodidae) vectors of Lyme disease organisms (Borrelia burgdorferi) in Florida. Fla Dept Agric. and Consumer Serv. Division of Plant Industry. Entomol. Circular n⿳326.

Callister S.M., Case K.L. \& Schell R.F. 1990. Diagnostic testing for Lyme disease. Labmedica, feb./mar.:11-14.

Callow L.L. 1967. Observations on tick-transmitted spirochaetes of cattle in Australia and South Africa. Brit. Vet. J. 123:492-497.

Canica M.M., Nato F., Merle L.D., Mazie J.C., Baranton G. \& Postic D. 1993. Monoclonal antibodies for identification of Borrelia afzelli sp. nov. associated with late cutaneous manifestations of Lyme borreliosis. Scand. J. Infect. Dis. 25:441-448.

Cerri D., Farina R., Andreani E., Nuvoloni R. \& Pedrini A. 1994. Experimental infection of dogs with Borrelia burgdorferi. Res. Vet. Sci. 57:256-258.

CDC. 1997. Lyme disease - United States, 1996. MMWR 46(23):531-535

Ciceroni L., Bartoloni A., Guglielmetti P., Paradisi F., Barahona H. G., Roselli M., Ciarrocchi S. \& Cacciapuoti B. 1994. Prevalence of antibodies to Borrelia burgdorferi, Borrelia parkeri and Borrelia turicatae in human settlements of the Codillera Province, Bolivia. J. Trop. Med. Hyg. 97:13-17.

Chen S., Dumler J.S., Bakker J.S. \& Walker D.H. 1994. Identification of a 
granulocytotropic Ehrlichia species as the etiologic agent of human disease. J. Clin. Microbiol. 32(3):589-595.

Chu H.J., Chavez Jr. L.G., Blumer B.M., Sebring R.W., Wasmoen T.L. \& Acree W.M. 1992. Immunogenicity and efficacy study of a commercial Borrelia burgdorferi bacterin. J. Am. Vet. Med. Assoc. 201(3):403-411.

Cohen N.D. \& Cohen D. 1990. Borreliosis in horses: a comparative review. The Compendium 12(10):1449-1458.

Cohen N.D., Heck F.C., Heim B., Flad D.M., Bosler E.M. \& Cohen D. 1992. Seroprevalence of antibodies to Borrelia burgdorferi in a population of horses in central Texas. J. Am. Vet. Med. Assoc. 201(7):1030-1034.

Costa I.P., Yoshinari N.H., Barros P.J.L., Bonoldi V.L.N., Leon E.P., Zeitune A.D. \& Cossermelli W. 1996. Doença de Lyme em Mato Grosso do Sul: relato de três casos clínicos, incluindo o primeiro relato de meningite de Lyme no Brasil. Revta Hosp. Clin. Fac. Med. S. Paulo 51(6):253-257.

Coughlin R.T., Fish D., Mather T.N., Ma J., Pavia M. \& Bulger P. 1995. Protection of dogs from Lyme disease with a vaccine containing outer surface protein (Osp) a, OspB, and the saponin adjuvant QS21. J. Infect. Dis. 171:10491052.

Coyle P.K. 1993. Lyme Disease. Mosby Year Book, Boston. 235 p.

Craft J.E., Grodzicki R.L. \& Steere A.C. 1984. Antibody response in Lyme disease: evaluation of diagnostic tests. J. Infec. Dis. 149(5):789-795.

Craft J.E., Fischer D.K., Shimamoto G.T. \& Steere A.C. 1986. Antigens of Borrelia burgdorferi recognized during Lyme disease. J. Clin. Invest. 78: 934-939.

Dalgliesh R.J. \& Stewart N.P. 1976. Simulation of the development of infective Babesia bovis (B. argentina) in unfed Boophilus microplus larvae. Aust. Vet. J. 52:543.

Dawson J.E., Stallknecht D.E., Howerth E.W., Warner C., Biggie K., Davidsonson W.R., Lockhart J.M., Nettles V. F., Olson J.G. \& Childs J.E. 1994. Susceptibility of white-tailed deer (Odocoileus virginianus) to infection with Ehrlichia chaffeensis, the etiologic agent of human ehrlichiosis. J. Clin. Microbiol. 32(11):2725-2728

Diab F.M. \& Soliman Z.R. 1977. An experimental study of Borrelia anserina in four species of Argas tick. 1. Spirochete localization and densities. Z. Parasitenk. 53:201-212.

Dodge R.W. 1973. Culture of ethiopian Borrelia recurrentis. Appl. Microbiol. 25(6):935-939.

Dorward D.W., Schwan T.G. \& Garon C.F. 1991. Immune capture and detection of Borrelia burgdorferi antigens in urine, blood, or tissue from infected ticks, mice, dogs and humans. J. Clin. Microbiol. 26(9):1162-1170.

Donoghue A.R. \& Van Veen T.W. S. 1989. Investigating cross-reactions between Leptospira and Borrelia. J. Am. Vet. Med. Assoc. 195(11):1460-1462.

Dressler F., Whalen J.A., Reinhardt B.N. \& Steere A.C. 1993. Western blotting in the serodiagnosis of Lyme disease. J. Infect. Dis. 167:392-400.

Dumler J.S., Asanovich K.M., Bakken J.S., Richter P., Kimsey R. \& Madigan J.E. 1995. Serologic cross-reactions among Ehrlichia equi, Ehrlichia phagocytophila and human granulocytic ehrlichia. J. Clin. Microbiol. 33(5):1098-1103.

Duray P.H. 1993. Histopathology of human borreliosis, p. 49-58. In: Coyle P.K. (ed.) Lyme Disease. Mosby Year Book, Boston.

Engstrom S.M., Shoop E. \& Johnson R.C. 1995. Immunoblot interpretation criteria for serodiagnosis of early Lyme disease. J. Clin. Microbiol. 33(2):419427.

Eremeeva M., Balayeva N., Roux V., Ignatovich V., Kotsinjan M. \& Raoult D. 1995. Genomic and proteinic characterization of strain S, a rickettsia isolated from Rhipicephalus sanguineus ticks in Armenia. J. Clin. Microbiol. 33(10):2738-2744.

Euzeby J.P. 1995. Les espéces et les genres bactériens d'intérêt vétérinaire décrits en 1994. Revue Méd. Vét. 146:3-22.

Ewing C., Scorpio A., Nelson D.R. \& Mather T.N. 1994. Isolation of Borrelia burgdorferi from saliva of the tick vetor, Ixodes scapularis. J. Clin. Microbiol. 32(3):755-758

Falco C.R. \& Fish D. 1988. Ticks parasitizing humans in a Lyme disease endemic area of southern New York State. Am. J. Epidemiol. 128:1146-1152.
Falco C.R. \& Fish D. 1989. Potential for exposure to tick bites in recreational parks in a Lyme disease endemic area. Am. J. Public. Health 79:12-15.

Falco C.R., Daniels T.J. \& Fish D. 1995. Increase in abundance of immature Ixodes scapularis (Acari: Ixodidae) in an emergent Lyme disease endemic area. J. Med. Entomol. 32(4) 522-526.

Felsenfeld O. 1965. Borreliae, human relapsing fever and parasite-vector-host relationships. Bacteriol. Rev. 11:1378-1380.

Fikrig E., Telford S.R.I., Barthold S.W., Kantor F.S., Spielman A. \& Flavell R.A. 1992. Elimination of Borrelia burgdorferi from vector ticks feeding on OspAimmunized mice. Proc. Nat. Acad. Sci. USA 89:5418-5421.

Filgueira A.L., Troppe B. M. \& Gontijo Filho P.P. 1989. Doença de Lyme. Rio Dermatológico 2(1):1.

Fingerle V., Hauser U., Liegl G., Petko B., Preac-Mursic V. \& Wilske B. 1995. Expression of outer surface proteins $\mathrm{A}$ and $\mathrm{C}$ of Borrelia burgdorferi in Ixodes ricinus. J. Clin. Microbiol. 33(7):1867-1869.

Fonseca A.H., Soares C.O., Cruz F.C.M. \& Yoshinari N.H. 1994. Doença de Lyme em bovinos e caninos no estado do Rio de Janeiro. XXIII Congr. Bras. Med. Vet., Recife, Pernambuco, p.123.

Fonseca A.H., Soares C.O., Ishikawa M.M., Massard C.L. \& Yoshinari N.H. 1995a. Detection of Borrelia sp. in opossum (Marsupialia: Didelphidae) in Brazil. An. XXV Congr. World Vet. Assoc., XX Congr. World Small Animal Vet. Assoc., Yokohama, Japão, p.283.

Fonseca A.H., Soares C.O., Ishikawa M.M., Massard C.L. \& Yoshinari N.H. 1995b. Lyme borreliosis sorology in cattle and dogs in Brazil. An. XXV Congr. World Vet. Assoc., XX Congr. World Small Animal Vet. Assoc., Yokohama, Japão, p.283.

Fonseca A.H., Ishikawa M.M., Soares C.O., Massard C.L. \& Yoshinari N.H. 1996. Lyme borreliosis serology in cattle in Brazil. Revta Univ. Rural., Sér. Cienc. da Vida, Rio de J., 18(1/2):85-89.

Frank J.C. 1989. Taking a hard look at Borrelia burgdorferi. J. Am. Vet. Med. Assoc. 194(11):1521.

Garcia-Monco J.C., Villar B.F., Alen J.C. \& Benach J.L. 1990. Borrelia burgdorferi in the central nervous system: experimental and clinical evidence for early invasion. J. Infect. Dis. 161:1187-1193.

Garcia-Monco J.C. 1993. European Lyme disease, p. 219-225. In: Coyle P.K. (ed.) Lyme Disease. Mosby Year Book, Boston.

Garin C.H. \& Bujadoux C.H. 1922. Paralysie par les tiques. J. Med. Lyon 71:765767.

Garnham P.C.C. 1966. Malaria parasites and other haemosporidia. Blackwell Scientific Publications Oxford. 1114 p.

Gern L. \& Rais O. 1996. Efficient transmission of Borrelia burgdorferi between cofeeding Ixodes ricinus ticks (Acari: Ixodidae). J. Med Entomol. 33(1):189192.

Gill J.S., Mclean R.G., Shriner R.B. \& Johnson R.C. 1994. Serologic surveillance for the Lyme disease spirochete, Borrelia burgdorferi, in Minnesota by using white-tailed deer as sentinel animals. J. Clin. Microbiol. 32(2):444-451.

Golighthly M.G. 1993. Antibody assays, p 115-120. In: Coyle P.K. (ed.) Lyme Disease. Mosby Year Book, Boston.

Grauer G.F., Burgess E.C., Cooley A.J. \& Hagee J.H. 1988. Renal lesions associated with Borrelia burgdorferi infection in a dog. J. Am. Vet. Med. Assoc. 193(2):237-239.

Greene R.T., Walker R.L., Nicholson W.L., Heidner H.W., Levine J.F., Burgess E.C., Wyand M., Breitschwerdt E.B. \& Berkhoff H.A. 1988. Immunoblot analysis of immunoglobulin $\mathrm{G}$ response to the Lyme disease agent (Borrelia burgdorferi) in experimentally and naturally exposed dogs. J. Clin. Microbiol. 26(4):648-653.

Greene R.T., Nicholson W.L., Breitschwerdt E.B. \& Levine J.F. 1989. Taking a second hard look at Borrelia burgdorferi. J. Am. Vet. Med. Assoc. 195(5):562563.

Greene R.T. 1990. An update on the serodiagnosis of canine Lyme borreliosis. J. Vet. Intern. Med. 4:167-171.

Grodzicki R.L. \& Steere A.C. 1988. Comparison of immunoblotting and indirect 
enzyme-linked immunosorbent assay using different antigen preparations for diagnosing early Lyme disease. J. Infect. Dis. 157(4):790-797.

Grund S., Nattermann H. \& Horsch F. 1995. Electron-microscopic examination of spirochaetes in dermatitis digitales lesions in cows. J. Vet. Med. 42:533542 .

Gustafson J.M., Burgess E.C., Wachal M.D. \& Steinberg H. 1993. Intrauterine transmission of Borrelia burgdorferi in dogs. Am. J. Vet. Res. 54(6):882- 890.

Hard S. 1966. Erythema chronicum migrans (Afzelii) associated with mosquito bite. Acta Derm. Venereol. 46:473.

Hellerstrom S. 1930. Erythema chronicum migrans afzelii. Acta Derm. Venereol. 11:315-318.

Hellerstrom S. 1950. Erythema chronicum migrans afzelii with meningitis. South Med. J. 43:330-334.

Herxheimer K. \& Hartmann K.U. 1902. Acrodermatitis chronica atrophicans. Arch. Dermatol. Syph. 61(57):255-300.

Hoogstraal H. 1979. Ticks and spirochetes. Acta Trop. 36:133-136.

Hoogstraal H. 1985. Argasid and nuttalliellid ticks as parasites and vectors. Adv. Parasitol. 24:135-238.

Hubalek Z., Anderson J.F., Halouzka J. \& Hajek V. 1996. Borreliae in immature Ixodes ricinus (Acari: Ixodidae) ticks parasitizing birds in the Czech Republic. J. Med. Entomol. 33(5):766-771.

Hyde F.W., Johnson R.C., White T.J. \& Shelburne C.E. 1989. Detectin of antigens in urine of mice and humans infected with Borrelia burgdorferi, etiologic agent of Lyme disease. J. Clin. Microbiol. 27(1):58-61.

Iqbal Z. \& Rikihisa Y. 1994. Reisolation of Ehrlichia canis from blood and tissues of dogs after doxycycline treatment. J. Clin. Microbiol. 32(7):1644-1649.

Iqbal Z., Chaichanasiriwithaya W. \& Rikihisa Y. 1994. Comparison of PCR with other tests for early diagnosis of canine ehrlichiosis. J. Clin. Microbiol. 32(7):1658-1662.

Irvin A.D., Omwoyo P., Purnell R.E., Pierce M.A. \& Schiemann B. 1973. Blood parasites of the impala (Aepyceros melampus) in the Serengeti National Park. Vet. Rec. 93:200-203.

Ishikawa M.M. 1996. Epidemiologia da borreliose de Lyme em bovinos na região sudeste do Brasil e padronização do diagnóstico sorológico. Tese de Mestrado, UFRRJ, Rio de Janeiro. 51p.

Ishikawa M.M., Fonseca A.H., Soares C.O., Massard C.L. \& Yoshinari N.H. 1997. Padronização de ensaio imunoenzimático ELISA indireto para pesquisa de anticorpos IgG contra Borrelia burgdorferi em bovinos. Revta Bras. Med. Vet. 19(4):166-168.

Isogai E., Isogai H., Kawabata T., Masuzawa T., Yanagihara Y., Kimura K., Sakai T., Azuma Y., Fujii N. \& Ohno S. 1994. Lyme disease spirochetes in a wild fox (Vulpes vulpes schrencki) and in ticks. J. Wild. Dis. 30(3):439-444.

Jaenson T.G.T. 1991. The epidemiology of Lyme borreliosis. Parasitol. Today $7(2): 39-45$

Jaenson T.G.T. \& Talleklint L. 1996. Lyme borreliosis spirochetes in Ixodes ricinus (Acari: Ixodidae) and the varying hare on isolated islands in the Baltic Sea. J. Med. Entomol. 33(3):339-343.

Jobe D.A., Callister S.M. \& Schell R.F. 1993. Recovery of Borrelia burgdorferi by filtration. J. Clin. Microbiol. 31(7):1896-1898.

Jobe D.A., Callister S.M., Lim L.C.L., Lovrich S.D. \& Schell R.F. 1994. Ability of canine Lyme disease vaccine to protect hamsters against infection with several isolates of Borrelia burgdorferi. J. Clin. Microbiol. 32(3):618-622.

Johnson R.C., Schimid G.P., Hyde F.W., Steigerwalt A.G. \& Brenner D.J. 1984 Borrelia burgdorferi sp. nov.: etiologic agent of Lyme disease. Int. J. Syst. Bacteriol. 34:496.

Johnson R.C., Burgdorfer W., Lane R.S., Barbour A.G., Hayes S.F. \& Hyde F.W. 1987. Borrelia coriaceae sp. nov. putative agent of epizootic bovine abortion. Int. J. Syst. Bacteriol. 37:72-74.

Joppert A.M. 1995. Estudo soro-epidemiológico da infecção por Borrelia burgdorferi em cães da região de Cotia, São Paulo. Tese Mestrado, FMVZUSP, São Paulo. 83p.
Kantor F.S. 1994. Disarming Lyme disease. Scient. Am., September:20-25.

Karch H., Huppertz H.I., Böhme M., Schmidt H., Wiebecke D. \& Schwarzkoff A. 1994. Demonstration of Borrelia burgdorferi DNA in urine samples from healthy humans whose sera contain B. burgdorferi-specific antibodies. J. Clin. Microbiol. 32(9):2312-2314.

Kawabata M., Baba S., Iguchi K., Yamaguti N. \& Russel H. 1987. Lyme disease in Japan and its possible incriminated tick vector, Ixodes persulcatus. J. Infect. Dis. 156(5):854.

Kawabata H., Masuzawa T. \& Yanagihara Y. 1993. Genomic analysis of Borrelia japonica sp. nov. isolated from Ixodes ovatus in Japan. Microbiol. Immunol. 37:843-848.

Kimura K., Isogai E., Isogai H., Kamewaka Y., Nishikawa T., Ishii N. \& Fujii N. 1995. Detection of Lyme disease spirochetes in skin of naturally infected wild sika deer (Cervus nippon yesoensis) by PCR. Appl. Environ. Microbiol. 61(4):1641-1642.

Koch H.T., Kambeva L., Ocama J.G.R., Munatswa F.C., Franssen F.R.J., Uilenberg G., Dolan T.T. \& Norval R.A.I. 1990. Immunization of cattle against Theileria parva bovis and their exposure to natural challenge. Vet. Parasitol. 37:185196.

Kornblatt A.N., Urband P.H. \& Steere A.C. 1985. Arthritis caused by Borrelia burgdorferi in dogs. J. Am. Vet. Med. Assoc. 186:960-964.

Kramer L.D., Hardy J.L. \& Presser S.B. 1983. Effect of temperature of extrinsic incubation on the vector competence of Culex tarsalis for western equine encephalomyelitis virus. Am. J. Trop. Med. .Hyg. 32:1130-1139.

Krieg N.R. \& Holt J.G. 1984. Bergey's Manual of Sistematic Bacteriology. Vol. 1. 8th Edition, Williams \& Wilkins, London, p.57-62.

Kuiper H., Van Dam A.P., Spanjaard L., Jongh B.M., Widjojokusumo A., Ramselaar T.C.P., Cairo I., Vos K. \& Dankert J. 1994. Isolation of Borrelia burgdorferi from biopsy specimens taken from healthy-looking skin of patients with Lyme borreliosis. J. Clin. Microbiol. 32(3):715-720.

Kurtenbach K., Kampen H., Dizij A., Arndt S., Seitz H.M., Schaible U.E. \& Simon M. 1995. Infestation of rodents with larval Ixodes ricinus (Acari: Ixodidae) is an important factor in the transmission cycle of Borrelia burgdorferi s.1. in German woodlands. J. Med. Entomol. 32(6):807-817.

Lane R.S., Burgdorfer W., Hayes S.F. \& Barbour A.G. 1985. Isolation of a spirochete from the soft tick, Ornithodorus coriaceus: a possible agent of epizootic bovine abortion. Science 230:85-87.

Lane R.S. \& Burgdorfer W. 1987. Transovarial and transstadial passage of Borrelia burgdorferi in the western black-legged tick, Ixodes pacificus (Acari: Ixodidae). Am. J. Med. Hyg. 37(1):188-192.

Lane R.S. \& Manweiler S.A. 1988. Borrelia coriaceae in its tick vector, Ornithodorus coriaceus (Acari: Argasidae), with emphasis on transstadial and transovarial infection. J. Med. Entomol. 25(3):172-177.

Lane R.S., Piesman J. \& Burgdorfer W. 1991. Lyme borreliosis: relation of its causative agent to its vectors and hosts in North America and Europe. Annu. Rev. Entomol. 36 587-609.

Lane R.S., Brown R.N., Piesman J. \& Peavey C. 1994. Vector competence of Ixodes pacificus and Dermacentor occidentalis (Acari: Ixodidae) for various isolates of Lyme disease spirochetes. J. Med. Entomol. 31(3):417-424.

Lebech A.M. \& Hansen K. 1992. Detectin of Borrelia burgdorferi DNA in urine samples and cerebrospinal fluid samples from patients with early and late Lyme neuroborreliosis by poLymerase chain reaction. J. Clin. Microbiol. 30(7):1646-16-53.

Lebech A.M., Clemmensen O. \& Hansen K. 1995. Comparison of in vitro culture, immunohistochemical staining, and PCR for detection of Borrelia burgdorferi in tissue from experimentally infected animals. J. Clin. Microbiol. 33(9):23282333.

Le Fleche A., Postic D., Girardet K., Peter O. \& Baranton G. 1997. Characterization of Borrelia lusitaniae sp. nov. by $16 \mathrm{~S}$ ribosomal DNA sequence analysis. Intern. J. Syst. Bacteriol. 47(4):921-925.

Lemos E.R.S., Machado R.D. \& Coura J.R. 1994. Rocky mountain spotted fever in an endemic area in Minas Gerais, Brazil. Mem. Inst. Oswaldo Cruz 89(4):497-501. 
Levy S.A. \& Dreesen D.W. 1992. Lyme borreliosis in dogs. Canine Pract. 17(2):514.

Levy S.A. \& Duray P.H. 1988. Complete heart block in a dog seropositive for Borrelia burgdorferi. J. Vet. Intern. Med. 2:138-144.

Levy S.A. \& Magnarelli L.A. 1992. Relationship betwwen development of antibodies to Borrelia burgdorferi in dogs and the subsequent development of limb/joint borreliosis. J. Am. Vet. Med. Assoc. 200(3):344-347.

Lewengrub S., Rudzinska M.A., Piesman J., Spielman A. \& Zung J.L. 1989. The influence of heat on the development of Babesia microti in unfed nymphs of Ixodes dammini . Can. J. Zool. 66:1342-1345.

Lienbling M.R., Nishio M.J., Rodriguez A., Sigal L.H., Jin T. \& Louie J.S. 1993. The poLymerase chain reaction for the detection of Borrelia burgdorferi in human body fluids. Arth. Rheum. 36(5):665-675.

Lipschultz B. 1913. Über eine seltene Erythemform (Erythema chronicum migrans). Arch. Derm. Syph. 118:349.

Lissman B.A., Bosler E.M., Camay H., Ormiston B.G. \& Benach J.L. 1984. Spirochetes associated arthritis (Lyme disease) in a dog. J. Am. Vet. Med. Assoc. 185(2):219-220.

Lopes C.W.G. 1976. Ocorrência de protófitas em ruminantes e suínos doméstico, ainda não descritos no Brasil. Tese de Mestrado, UFRRJ, Rio de Janeiro. $52 \mathrm{p}$.

Lord R.D., Lord V.R., Humphreys J.G. \& Mclean R.G. 1994. Distribution of Borrelia burgdorferi in host mice in Pennsylvania. J. Clin. Microbiol. 32(10):2501-2504.

Ma J., Bulger P.A., Dante S., Davis D.V.R., Palmer B.P. \& Coughlin R.T. 1995. Characterization of canine humoral immune responses to outer surface protein subunit vaccines and to natural infection by Lyme disease spirochetes. J. Infect. Dis. 171:909-915.

Madigan J.E. 1993. Lyme disease in horses. The Backstretch, February:12-16.

Magnarelli L.A., Anderson J.F. \& Burgdorfer W. 1979. Rocky mountain spotted fever in Connecticut: human cases, spotted-fever group rickettsiae in ticks, and antibodies in mammals. Am. J. Epidemiol. 110(2):148-155.

Magnarelli L.A., Meegan J.M., Anderson J.F. \& Chappell W.A. 1984. Comparison of an indirect fluorescent-antibody test with an enzyme-linked immunosorbent assay for serological studies of Lyme disease. J. Clin. Microbiol. 20:181-184.

Magnarelli L.A., Anderson J.F., Kaufmann A.F., Lieberman L.L. \& Whitney G.D. 1985. Borreliosis in dogs from southern Connecticut. J. Am. Vet. Med. Assoc. 189:955-959.

Magnarelli L.A., Anderson J.F., Apperson C.S., Fish D., Johnson R.C. \& Chappell W.A. 1986. Spirochetes in ticks and antibodies to Borrelia burgdorferi in white tailed deer from Connecticut, New York state, and North Caroline. J. Wildl. Dis. 22:178-188.

Magnarelli L.A., Anderson J.F., Schreier A.B. \& Ficke C.M. 1987. Clinical and serologic studies of canine borreliosis. J. Am. Vet. Med. Assoc. 191:10891094.

Magnarelli L.A. \& Anderson J.F. 1988. Enzyme-linked immunosorbent assays for the detection of class-specific immunoglobulins to Borrelia burgdorferi. Am. J. Epidemiol. 127(4):818-825.

Magnarelli L.A. 1989. Quality of Lyme disease tests. J. Am. Med. Assoc. 262(24):3464-3465.

Magnarelli L.A. \& Anderson J.F. 1989. Class-specific and polyvalent enzymelinked immunosorbent assays for detection of antibodies to Borrelia burgdorferi in equids. J. Am. Vet. Med. Assoc. 195(10):1365-1368.

Magnarelli L.A., Anderson J.F. \& Schreier A.B. 1990a. Persistence of antibodies to Borrelia burgdorferi in dogs of New York and Connecticut. J. Am. Vet. Med. Assoc. 196(7):1064-1068.

Magnarelli L.A., Anderson J.F., Levine H.R. \& Levy S.A. 1990b. Tick parasitism and antibodies to Borrelia burgdorferi in cats. J. Am. Vet. Med. Assoc. 197(1):63-66.

Magnarelli L.A., Anderson J.F., Johnson R.C., Nadelman R.B. \& Wormser G.P. 1994a. Comparison of different strains of Borrelia burgdorferi sensu lato used as antigens in enzyme-linked immunosorbent assays. J. Clin. Microbiol. 32(5):1154-1158.

Magnarelli L.A., Anderson J.F. \& Stafford K.C. 1994b. Detection of Borrelia burgdorferi in urine of Peromyscus leucopus by inhibition enzyme-linked immunosorbent assay. J. Clin. Microbiol. 32(3):777-782.

Magnarelli L.A., Dumler J.S., Anderson J.F., Johnson R.C. \& Fikrig E. 1995a. Coexistence of antibodies to tick-borne pathogens of babesiosis, ehrlichiosis, and Lyme borreliosis in human sera. J. Clin. Microbiol. 33(11):3054-3057.

Magnarelli L.A., Stafford K.C., Mather T.N., Yeh M.T., Horn K.D. \& Dumler J.S. 1995b. Hemocytic rickettsia-like organisms in ticks: serologic reactivity with antisera to ehrlichia and detection of DNA of agent of human granulocytic ehrlichiosis by PCR. J. Clin. Microbiol. 33(10):2710-2714.

Magnarelli L.A., Anderson J.F. \& Johnson R.C. 1995c. Analyses of mammalian sera in enzyme-linked immunosorbent assays with different strains of Borrelia burgdorferi sensu lato. J. Wild. Dis. 31(2):159-165.

Marconi R.T., Liveris D. \& Schwartz I. 1995. Identification of novel insertion elements, restriction fragment length polymorphism patterns, and discontinuous 23S rRNA in Lyme disease spirochetes: phylogenetic analyses of rRNA genes and their intergenic spacers in Borrelia japonica sp. nov. and genomic group 21038 (Borrelia andersonii sp. nov.) isolates. J. Clin. Microbiol. 33(4):2427-2434.

Marcus L.C., Patterson M.M. \& Gilfillan R.E. 1985. Antibodies to Borrelia burgdorferi in New England horses. Am. J. Vet. Res. 46:2570.

Manweiler S.A., Lane R.S., Block W.M. \& Morrison M.L. 1990. Survey of birds and lizards for ixodid ticks (Acari) and spirochetal infection in northern California. J. Med. Entomol. 27(6):1011-1015.

Massard C.L., Lopes C.W.G., Cunha D.W. \& Massard C.A. 1976. The occurrence of an intraerythrocytic microorganism Neitziella rezendei gen. nov. sp. nov. (Microtatobiotes, Rickettsiales) of poultry in Brazil. Acta Trop. 33(1):3-14.

Mast W.E. \& Burrows W.M. 1976. Erythema chronicum migrans in the United States. J. Am. Med. Assoc. 236:859.

Masuzawa T., Beppu Y., Kawabata H., Yanagihara Y., Iwamoto Y., Shimizu T. \& Johnson R.C. 1992. Experimental Borrelia burgdorferi infection of outbred mice. J. Clin. Microbiol. 30(11):3016-3018.

Masuzawa T., Suzuki H., Kawabata H., Ishiguro F., Takada N., Yano Y. \& Yanagihara I. 1995. Identification of spirochete isolated from wild rodents in Japan as Borrelia japonica. J. Clin. Microbiol. 33(5):1392-1394.

Mather T.N. \& Mather M.E. 1990. Intrinsic competence of three ixodid ticks (Acari) as vectors of the Lyme disease spirochete. J. Med. Entomol. 27(4):646650.

Mather T.N., Fish D. \& Coughlin R.T. 1994. Competence of dogs as reservoirs for Lyme disease spirochetes (Borrelia burgdorferi). J. Am. Vet. Med. Assoc. 205(2):186-188.

Matton P. \& Melckebeke H.V. 1990. Bovine borreliosis: comparison on simple methods for detection of the spirochaete in the blood. Trop. Anim. Hlth Prod. 22:147-152.

Matuschka F.R. \& Spielman A. 1992. Loss of Lyme disease spirochetes from Ixodes ricinus ticks feeding on european blackbirds. Exp. Parasitol. 74:151158.

Maupin G.O., Gage K.L., Piesman J., Montenieri J., Sviat S.L., Zanden L.V., Happ C.M., Dolan M. \& Johnson B.J.B. 1994. Discovery of an enzootic cycle of Borrelia burgdorferi in Neotoma mexicana and Ixodes spinipalpis from Northern Colorado, an area where Lyme disease is nonendemic. J. Infect. Dis. 170:636-643.

Mckenna P., Clement J., Van Dijck D., Lauwerys M., Carey D., Van Den B. \& Bigaignon G. 1995. Canine Lyme disease in Belgium. Vet. Rec. 136:224-247.

Mclean D.M., Miller M.A. \& Grass P.N. 1975. Dengue virus transmission by mosquitoes incubated at low temperatures. Mosq. News 35:322-327.

Mclean R.G., Ubico S.R. \& Cooksey L.M. 1993. Experimental infection of the eastern chipmunk (Tamias striatus) with the Lyme disease spirochete (Borrelia burgdorferi). J. Wild. Dis. 29(4):527-532.

Meredith S.E.O., Kroon N.C.M., Sondorp E., Seaman J., Goris M.G.A., Van Ingen 
C.W., Oosting H., Schoone G.J., Terpstra W.J. \& Oskam L. 1995. Leish-kit, a stable direct agglutination test based on freeze-dried antigen for serodiagnosis of visceral leishmaniasis. J. Clin. Microbiol. 33(7):1742-1745.

Mitchell P.D., Reed K.D., Aspeslet T.L., Vandermause M.F. \& Melski J.W. 1994. Comparison of four immunoserologic assays for detection of antibodies to Borrelia burgdorferi in patients with culture-positive erythema migrans. J. Clin. Microbiol. 32(8):1958-1962.

Miyamoto K., Nakao M., Fujita H. \& Sato F. 1993. The ixodids ticks on migratory birds in Japan and the isolation of Lyme disease spirochetes from birdfeeding ticks. Jap. J. Sanit. Zool. 44:315-326.

Miyamoto K., Nakao M., Uchikawa K. \& Fujita H. 1992. Prevalence of Lyme borreliosis spirochetes in ixodid ticks of japan, with special reference to a new potential vector, Ixodes ovatus (Acari: Ixodidae). J. Med. Entomol. 29 (2):216-220.

Moter S.E., Hofmann H., Wallish R., Simon M.M. \& Kramer M.D. 1994. Detection of Borrelia burgdorferi sensu lato in lesional skin of patients with erythema migrans and acrodermatitis chronica atrophicans by ospA-specific PCR. J. Clin. Microbiol. 32(12):2980-2988.

Mouritsen C.L., Wittwer C.T., Litwin C.M., Yang L., Weis J.J., Martins T.B., Jaskowski T.D. \& Hill H.R. 1996. PoLymerase chain reaction of Lyme disease. Am. J. Clin. Pathol. 105(5):647-654.

Nakao M., Miyamoto K. \& Fukunaga M. 1994. Lyme disease spirochetes in Japan: enzootic transmission cycles in birds, rodents, and Ixodes persulcatus ticks. J. Infect. Dis. 170:878-882.

Nakao M., Miyamoto K., Uchikawa K. \& Fujita H. 1992. Characterization of Borrelia burgdorferi isolated from Ixodes persulcatus and Ixodes ovatus ticks in Japan. Am. J. Trop. Med. Hyg. 47(4):505-511.

Nakayama Y., Spielman A. \& James A.A. 1989. Protein synthesis induced by heat in an Ixodes tick. Insect Biochem. 19:731-736.

Neitz W.O. 1956. A consolidation of our knowledge of the transmission of tick-borne diseases. Onderstepoort J. Vet. Res. 27:115-163.

Nicholls T.H. \& Callister S.M. 1996. Lyme disease spirochetes in ticks collected from birds in midwestern United States. J. Med. Entomol. 33(3):379-383.

Ogden N.H., Carter S.D. \& Nuttall P.A. 1994. Evidence for the transmission of Lyme disease spirochete to sheep in Cumbria. Vet. Rec. 135:383-384.

Oksi J., Uksila J., Marjamaki M., Nikoskelainen J. \& Viljanen M.K. 1995. Antibodies against whole sonicated Borrelia burgdorferi spirochetes, 41 kilodalton flegellin, and P39 protein in patients with PCR or culture-proven late Lyme borreliosis. J. Clin. Microbiol. 33(9):2260-2264.

Oliver Jr. J.H., Owsler M.R., Hutchenson H.J., James A.M., Chen C., Irby W.S., Dotson E.M. \& Mclain D.K. 1993. Conspecificity of the ticks Ixodes scapularis and I. dammini (Acari: Ixodidae). J. Med. Entomol. 30:54-63.

Olsen B., Duffy D.C., Jaenson T.G.T., Gylfe A., Bonnedahl J. \& Bergstrom S. 1995. Transhemispheric exchange of Lyme disease spirochetes by seabirds. J. Clin. Microbiol. 33(12):3270-3274.

Osebold J.W., Spezialetti R., Jennings M.B., Pritchett R.F. \& Bushnell R.B. 1986. Congenital spirochetosis in calves: association with epizootic bovine abortion. J. Am. Vet. Med. Assoc. 188(4):371-375.

Pachner A.R. \& Steere A.C. 1984. Neurological findings of Lyme disease. Yale J. Biol. Med. 57:481-483.

Pachner A.R., Basta J., Delaney E. \& Hulinska D. 1995. Localization of Borrelia burgdorferi in murine Lyme borrelioses by electron microscopy. Am. J. Trop. Med. Hyg. 52(2):128-133.

Parker J.L. \& White K.W. 1992. Lyme borreliosis in cattle and horses: a review of the literature. Cornell Vet. 82:253-274.

Pavlovsky E.N. 1965. Natural Nidality of Transmissible Diseases. Peace Publishers, Moscow. 250p.

Pêssoa S.B. 1963. Parasitologia Médica. Ed. Guanabara Koogan, Rio de Janeiro. $849 \mathrm{p}$.

Pfister H.W., Wilske B. \& Weber K. 1994. Lyme borreliosis: basic science and clinical aspects. Lancet 343:1013-1016.

Piesman J., Mather T.N., Telford S.R. \& Spielman A. 1986. Concurrent Borrelia burgdorferi and Babesia microti infection in nymphal Ixodes dammini. J. Clin. Microbiol. 24(3):446-447.

Piesman J., Mather T.N., Sinsky R.J. \& Spielman A. 1987. Duration of tick attachment and Borrelia burgdorferi transmission. J. Clin. Microbiol. 25(8):557-558.

Piesman J., Oliver J.R. \& Sinsky R.J. 1990. Growth kinets of the Lyme disease spirochete (Borrelia burgdorferi) in the vector tick (Ixodes dammini). Am. J. Trop. Med. Hyg. 42:352-357.

Postic D., Belfazia J., Isogai E., Girons I.S., Grimont P.A.D. \& Baranton G. 1993. A new genomic species in Borrelia burgdorferi sensu lato isolated from japanese ticks. Res. Microbiol. 144:467-473.

Quinn P.J., Carter M.E., Markey B.K. \& Carter G.R. 1994. Clinical Veterinary Microbiology. First Edition. Wolfe Publishing, London, p.292-303.

Rahn D.W. \& Malawista S.E. 1991. Lyme disease: recommendations for diagnosis and treatment. Ann. Intern. Med. 114:472-481.

Randolph S.E. \& Craine N.G. 1995. General framework for comparative quantitative studies on tranmission of tick-borne disease using Lyme borreliosis in Europa as an example. J. Med. Entomol. 32(6):765-777.

Randolph S.E., Gern L. \& Nuttall P.A. 1996. Co-feeding ticks: epidemiological significance for tick-borne pathogen transmission. Parasitol. Today 12(12):472-479.

Rasiah C., Rauer S., Gassmann G.S. \& Vogt A. 1994. Use of a hybrid protein cositing of the varible region of the Borrelia burgdorferi flagellin and part of the 83-kDa protein as antigen for serodiagnosis of Lyme disease. J. Clin. Microbiol. 32(4):1011-1117.

Restrepo B.I., Carter C.J. \& Barbour A.G. 1994. Activation of a vmp pseudogene in Borrelia hermsii: an alternate mechanism of antigenic variation during relapsing fever. Mol. Microbiol. 13(2):287-299.

Ribeiro J.M.C. 1989. Role of saliva in tick/host interactions. Exp. Appl. Acarol. 7:15.

Ribeiro J.M.C., Makoul G.T., Levine J., Robinson D.R. \& Spielman A. 1985. Antihemostatic, antiinflammatory and immunosupressive properties of the saliva of a tick, Ixodes dammini. J. Exp. Med. 161:332-344.

Ribeiro J.M.C., Mather T.N., Peisman J. \& Spielman A. 1987. Dissemination and salivary delivery of Lyme disease spirochetes in vector ticks (Acari: Ixodidae). J. Med. Entomol. 24(2):201-205.

Richter Jr P.J., Kimsey R.B., Madigan J.E., Barlough J.E., Dumler J.S. \& Brooks D.L. 1996. Ixodes pacificus (Acari: Ixodidae) as a vector of Ehrlichia equi (Rickettsiales: Ehrlichieae). J. Med. Entomol. 33(1):1-5.

Rikihisa Y., Ewing S.A. \& Fox J.C. 1994. Western immunoblot analysis of Ehrlichia chaffensis, E. canis, or E. ewingii infections in dogs and humans. J. Clin. Microbiol. 32(9):2107-2112.

Roitt I., Brostoff J. \& Male D. 1997. Imunologia. $4^{\mathrm{a}}$ ed. Ed. Manole, São Paulo. p.28.14.

Rothwell J.T., Christie B.M., Williams C. \& Walker K.H. 1989. Suspected Lyme disease in a cow. Aust. Vet. J. 66(9):296-298.

Russell H., Sampson J.S., Schimid G.P., Wilkinson H.W. \& Plikaytis B. 1984. Enzyme-linked immunosorbent assay and indirect immunofluorescence assay for Lyme disease. J. Infect. Dis. 149(3):465-470.

Schoeler G.B. \& Lane R.S. 1993. Efficiency of transovarial tranmission of the Lyme disease spirochete, Borrelia burgdorferi, in the western blacklegged tick, Ixodes pacificus (Acari: Ixodidae). J. Med. Entomol. 30(1):80-86.

Schwan T.G. 1996. Ticks and Borrelia: model systems for investigating pathogen-arthropod interactions. Infect. Agents Dis. 5(3):167-181.

Schwartz B.S., Ribeiro J.M.C. \& Goldstein M.D. 1990. Anti-tick antibodies: an epidemiologic tool in Lyme disease research. Am. J. Epidemiol. 132:58-66.

Schwartz B.S., Nadelman R.B., Fish D., Childs J.E., Forseter G. \& Wormser G.P. 1993. Entomologic and demographic correlates of anti-tick saliva antibody in a prospective study of tick bite subjects in Westchester County, New York. Am. J. Trop. Med. Hyg. 48(1):50-57.

Sexton D.J., Muniz M., Corey G.R., Breitschwerdt E.B., Hegarty B.C., Dumler S., Walker D.H., Pecanha P.M. \& Dietze R. 1993. Brazilian spotted fever in 
Espirito Santo, Brazil: description of a focus of infection in a new endemic region. Am. J. Trop. Med. Hyg. 49(2):222-226.

Shih C.M. \& Spielman A. 1993 . Topical prophylaxis for Lyme disease after tick bite in a rodent model. J. Infect. Dis. 168:1042-1045.

Shih C.M., Telford S.R. \& Spielman A. 1995a. Effect of ambient temperature on competence of deer ticks as hosts for Lyme disease spirochetes. J. Clin. Microbiol. 33(4):958-961.

Shih C.M., Spielman A. \& Telford S. R. 1995b. Short report: mode of action of protective immunity to Lyme disease spirochetes. Am. J. Trop. Med. Hyg. 52(1):72-74.

Silva A.M. \& Fikrig E. 1997. Borrelia burgdorferi genes selectively expressed in ticks and mammals. Parasitol. Today 13(7):267-270.

Smith R.D., Brener J., Osorno M. \& Ristic M. 1978. Pathobiology of Borrelia theileri in the tropical cattle tick, Boophilus microplus. J. Invertebr. Pathol. 32:182-190.

Smith R.D., Miranpuri G.S., Adams J.H. \& Ahrens E.H. 1985. Borrelia theileri: isolation from ticks (Boophilus microplus) and tick-borne transmission between splenectomized calves. Am. J. Vet. Res. 46(6):1396-1398.

Smith T. \& Kilborne F.L. 1893. Investigation of nature, causation and prevention of Texas or Southern cattle fever. Bull. Bur. Anim. Ind., U.S. Dep. Agric. 1:1.

Soares C.O. 1998. Estudo da borreliose canina: imunodiagnóstico, soroepidemiologia e análise interativa com a babesiose canina. Tese de Mestrado, UFRRJ, Rio de Janeiro. 80p.

Sonenshine D.E.. 1991. Biology of Ticks. Vol. 2. Oxford University Press, New York. 464p.

Sood S.K., Zemel L.S. \& Ilowite N.T. 1995. Interpretation of immunoblot in pediatric Lyme arthritis. J. Rheumatol. 22:758-761.

Spach D.H., Liles W.C., Campbell G.L., Quick R.E., Anderson Jr. D.E. \& Fritsche T.R. 1993. Tick-borne disease in the United States. New Engl. J. Med. 329(13):936-947.

Spielman A., Clifford C.M., Piesman J. \& Corwin M.D. 1979. Human babesiosis on Nantucket Island, USA: description of the vector, Ixodes (Ixodes) dammini, N. Sp. (Acarina: Ixodidae). J. Med. Entomol. 15(3):218-234.

Spielman A., Wilson M.L., Levine J.F. \& Piesman J. 1985. Ecology of Ixodes dammini - borne human babesiosis and Lyme disease. Ann.Rev. Entomol. 30:439-60.

Stafford K.C., Bladen V.C. \& Magnarelli L.A. 1995. Ticks (Acari: Ixodidae) infesting wild birds (aves) and white-footed mice in Lyme, CT. J. Med. Entomol. 32(4):453-466.

Stanchi N.O. \& Balague L.J. 1993. Lyme disease: antibodies against Borrelia burgdorferi in farm workers in Argentina. Revta Saúde Pública 27 (4):305307.

Steere A.C., Malawista S.E., Hardin J.A., Ruddy S., Askenase P.W. \& Andinan W.A. 1977a. Erythema chronicum migrans and Lyme arthritis: the enlarging clinical spectrum. Ann. Intern. Med. 86:685.

Steere A.C., Malawista S.E., Snydman D.R., Shope R.E., Andiman W.A., Ross M.R. \& Steere R.M. 1977b. Lyme arthritis: an epidemic of oligoarticular arthritis in children and adults in three Connecticut communities. Arth. Rheum. 20:7.

Steere A.C., Grodzicki R.L. \& Kornblatt A.N. 1983. The spirochetal etiology of Lyme disease. N. Engl. J. Med. 308(13):733-740.

Steere A.C. 1989. Lyme disease. New Engl. J. Med. 31:586-597.

Stiernstedt G.T., Granström M., Hederstedt B. \& Sköldenberg B. 1985. Diagnosis of spirochetal meningits by enzime-linked immunosorbent assay and indirect immunofluorescense assay in serum and and cerebrospinal fluid. J. Clin. Microbiol. 21(5):819-825.

Takada N., Ishiguro F., Iida H., YanoY. \& Fujita H. 1994. Prevalence of Lyme borrelia in ticks, especially Ixodes persulcatus (Acari: Ixodidae), in Central and Western Japan. J. Med. Entomol. 31(3):474-478.

Takahashi K., Isogai E., Isogai H., Takagi T., Sasaki K., Fujii N. \& Kimura K. 1993. Serological survey for Borrelia burgdorferi infection in cattle in Southern Hokkaido. J. Vet. Med. Sci. 55(6):921-924.
Talhari S., Talhari A.C. \& Ferreira L.C.L. 1992. Eritema chronicum migrans, eritema migratório, doença de Lyme ou borreliose de Lyme. Anais Bras. Dermatol. 67:205-209.

Talleklint L. \& Jaenson T.G.T. 1996. Relatioship between Ixodes ricinus density and prevalence of infection with Borrelia-like spirochetes and density of infected ticks. J. Med. Entomol. 33(5):805-811.

Telford S.R. \& Spielman A. 1989. Competence of a rabbit-feeding Ixodes (Acri: Ixodidae) as a vector of the Lyme disease spirochete. J. Med. Entomol. 26(2):118-121.

Telford S.R., Fikrig E., Barthold S.W., Brunet L.R., Spielman A. \& Flavell R.A. 1993. Protection against antigenically variable Borrelia burgdorferi conferred by recombinant vaccines. J. Exp. Med. 178:755-758.

Telford S.R., Armstrong P.M., Katavolos P., Fppa I., Garcia A.S.O., Wilson M.L. \& Spielman A. 1997. A new tick-borne encephalitis-like virus infecting New England deer ticks, Ixodes dammini. Emerging Infect. Dis. 3(2):165-170.

Uilenberg G. 1986. Highlights in recent research on tick-borne diseases of domestic animals. J. Parasitol. 72(4):485-491.

Urioste S., Hall L.R., Telford S.R. \& Titus R.G. 1994. Saliva of the Lyme disease vector, Ixodes dammini, blocks cell activation by a nonprostaglandin $\mathrm{E}_{2}$. dependent mechanism. J. Exp. Med. 180:1077-1085.

Van Der Ploeg L.H.T., Gottesdiener K. \& Lee M.G.S. 1992. Antigenic variation in african trypanosomes. Trends Genet. 8:452-457.

Versiani V. \& Gomes B.F. 1941. Sobre um novo hematozoário da galinha "Plasmodium juxtanucleare" N. Sp. Revta Brasil. Biol. 1(2):231-233.

Vivas R.I.R., Aguilar F.C., Alpízar J.L.D., Galera L.A.C. \& Calderón J.J.S. 1996. Detección de esoiroquetas del género Borrelia en hemolinfas de teleóginas de Boophilus microplus en el estado de Yucatán, México.Vet. Méx. 27(2):187188.

Walker D.H. \& Dumler J.S. 1996. Emergence of the ehrlichioses as human health problems. Emerg. Infect. Dis. 2(1):18-29.

Walker E.D., Mclean R.G., Smith T.W. \& Paskewitz S.M. 1996. Borrelia burgdorferi-infected Ixodes scapularis (Acari: Ixodidae) and Peromyscus leucopus in northeastern Wisconsin. J. Med. Entomol. 33(1):165-168.

Wallis R.C., Brown S.E., Kloter K.O. \& Main A.J. 1978. Erythema chronicum migrans and Lyme arthritis: field study of the ticks. Am. J. Epidemiol. 108:322-327.

Wang G., Van Dam A.P., Le Fleche A., Postic D., Peter O., Baranton G., Boer R., Spanjaard L. \& Dankert J. 1997. Genetic and phenotypic analysis of Borrelia valaisiana sp. nov. (Borrelia genomic groups VS116 and M19). Int. J. Syst. Bacteriol. 47(4):927-932.

Weber K. \& Pfister H.W. 1994. Clinical management of Lyme borreliosis. Lancet 343(23):1017-1020.

Wells S.J., Trent A.M., Robinson R.A., Knutson K.S. \& Bey R.F. 1993. Association between clinical lameness and Borrelia burgdorferi antibody in dairy cows. Am. J. Vet. Res. 54(3):398-405.

Willians L.R. \& Austin F.E. 1992. Hemolytic activity of Borrelia burgdorferi. Infect. Immun. 60(8):3224-3230.

Wouda W., Veen T.W.S.V. \& Barnes H.J. 1975. Borrelia anserina in chickens previously exposed to Borrelia theileri. Avian Dis. 19(1):209-210.

Yevich S.J., Sánchez J.L., Defraites R.F., Rives C.C., Dawson J.E., Uhaa I.J., Johnson B.J.B. \& Fishbein D.B. 1995. Seroepidemiology of infections due to spotted fever group rickettsiae and Ehrlichia species in military personnel exposed in areas of the United States where such infections are endemic. J. Infect. Dis. 171:1266-73.

Yoshinari N.H., Steere A.C. \& Cossermelli W. 1989. Revisão da borreliose de Lyme. Revta Assoc. Méd. Brasil. 35(1):34-37.

Yoshinari N.H., Barros P.J.L., Yassuda P., Baggio D., Steere A.C., Pagliarine R.C. \& Cossermelli W. 1992. Estudo epidemiológico da doença de Lyme no Brasil. Revta Hosp. Clín. Fac. Med. S. Paulo 47(2):71-75.

Yoshinari N.H., Oyafuso L.K., Monteiro F.G.V., Barros P.J.L., Cruz F.C.M., Ferreira L.G.E., Bonasser F., Baggio D. \& Cossermelli W. 1993a. Doença de Lyme: Relato de um caso observado no Brasil. Revta Hosp. Clin. Fac. Med. S. Paulo $48(4): 170-174$. 
Yoshinari N.H., Steere A.C., Barros P.J.L., Cruz F.M.C., Mendonça M., Oyafuso L.K., Levy L. \& Cossermelli W. 1993b. Lyme disease in Brasil: report of five cases. Revta Esp. Reumat. 20(supl.):6.

Yoshinari N.H., Barros P.J.L., Fonseca A.H., Bonoldi V.L.N., Battesti D.M., Schumaker T.S. \& Cossermelli W. 1995. Borreliose de Lyme - zoonose emergente de interesse multidisciplinar. News Lab 3(12):90-104.

Yoshinari N.H., Barros P.J.L., Bonoldi V.L.N., Ishikawa M.M., Battesti D.M.B., Pirana S., Fonseca A.H. \& Schumaker T.T. 1997. Perfil da borreliose de Lyme no Brasil. Revta Hosp. Clín. Fac. Med. S. Paulo 52(2):111-117.

Zaher M.A., Soliman Z.R. \& Diab F.M. 1977. An experimental study of Borrelia anserina in four species of Argas ticks. 2. Transtadial survival and transovarial transmission. Z. Parasitenk. 53:213-223.
Zbinden R., Goldenberger D., Lucchini G.M. \& Altwegg M. 1994. Comparison of two methods for detecting intrathecal synthesis of Borrelia burgdorferispecific antibodies and PCR for diagnosis of Lyme antibodies and PCR for diagnosis of Lyme neuroborreliosis. J. Clin. Microbiol. 32(7):1795-1798.

Zingg B.C. \& Lefebvre R.B. 1994. PoLymerase chain reaction for detection of Borrelia coriaceae, putative agent of epizootic bovine abortion. Am. J. Vet. Res. 55(11):1509-1515.

Zung J.L., Lewengrub M.A., Rudzinska A.M., Spielman A., Telford S.R. \& Piesman J. 1989. Fine strutural evidence for the penetration of the Lyme disease spirochete Borrelia burgdorferi through the gut tissues and salivary glands in Ixodes dammini. Can. J. Zool. 67:1737. 